\title{
Accountability democrática e a mudança da ordem política europeia ${ }^{1}$
}

Johan P. Olsen

University of Oslo, Noruega

Este artigo aborda o tema da accountability democrática e de uma Europa lutando para encontrar respostas viáveis para as questões de quem e o que deve constituir a "Europa" e como desenvolver instituições políticas legítimas para governá-la. O artigo trata dos problemas relacionados à ordem e à mudança políticas; às regras para a convivência; ao papel da política democrática na sociedade; às relações entre a organização política e a convivência civilizada; e ao estudo político. As democracias modernas convivem com conflitos não resolvidos e os regimes de accountability fazem parte de um arranjo institucional para preservar a ordem e a continuidade e também para criar dinâmicas de mudança. Os processos de responsabilização ocorrem dentro de ordens estabelecidas e não estabelecidas, e elas afetam e são afetadas pelas ordens existentes. Sem negar a importância dos interesses contundentes, das lutas de poder, do comportamento estratégico, dos jogos não cooperativos e das batalhas (re)distributivas, a atenção é direcionada para a busca da unidade, coesão política e solidariedade, com base no consentimento informado e voluntário das pessoas por meio da reflexão e deliberações fundamentadas entre indivíduos com diferentes valores, interesses, entendimentos e recursos.

Palavras-chave: accountability, democracia, legitimidade, participação política, controle social, política e governo

\footnotetext{
${ }^{1}$ Este artigo é uma versão traduzida (tradução de Fernando Filgueiras) para o português da conferência proferida no Encontro Geral do European Consortium for Political Research (ECPR), Oslo, 7 de setembro de 2017. Sou grato a Morten Egeberg, Fernando Filgueiras, Robert E. Goodin, Per Lægreid, James G. March, Agustín José Menéndez, Margo Meyer, Ludvig Norman, Helene Olsen, Yannis Papadopoulos, Víctor Pérez-Díaz e Olof Petersson pela ajuda. Como de costume, nenhuma dessas boas pessoas são responsáveis pelo produto final. Este artigo também foi publicado em inglês no European Law Journal, volume 23, issue 6, 2017.
}

[Artigo recebido em 1ㅇ de outubro de 2017. Aprovado em 6 de novembro de 2017.] 


\section{Accountability democrática y el cambio del orden político europeo}

Este artículo trata sobre la rendición de cuentas democrática y una Europa que lucha por encontrar respuestas viables a las preguntas de quién y qué constituirá "Europa" y cómo desarrollar instituciones políticas legítimas para gobernarla. El artículo es, sin embargo, sobre el orden político y el cambio, las reglas para vivir juntos, el papel de la política democrática en la sociedad y las relaciones entre organización política y coexistencia civilizada, y el estudio político. Las democracias modernas conviven con conflictos no resueltos y los regímenes de rendición de cuentas forman parte de un arreglo institucional para preservar el orden y la continuidad y también para crear dinámicas y cambios. Los procesos de rendición de cuentas tienen lugar dentro de las órdenes resueltas y no resueltas, y afectan y son afectados por las órdenes existentes. Sin negar la importancia de los intereses, las luchas por el poder, los comportamientos estratégicos, los juegos no cooperativos y las batallas (redistributivas), la atención está dirigida a la búsqueda de la unidad, la cohesión política y la solidaridad basada en el consentimiento informado y voluntario del pueblo mediante la reflexión y la deliberación razonada entre individuos con diferentes valores, intereses, entendimientos y recursos.

Palabras clave: accountability, democracia, legitimidad, participación política, control social, política y gobierno

\section{Democratic accountability and the changing European political order}

This article is about democratic accountability and a Europe struggling to find viable answers to the questions of who and what shall constitute "Europe" and how to develop legitimate political institutions for governing it. The article is, nevertheless, first and foremost about political order and change, rules for living together, the role of democratic politics in society and the relations between political organization and civilized coexistence, and the study of the political. Modern democracies live with unresolved conflict, and accountability regimes are part of an institutional arrangement for preserving order and continuity and also for creating dynamics and change. Accountability processes take place within settled and unsettled orders, and they affect and are affected by existing orders. Without denying the importance of contending interests, power struggles, strategic behavior, noncooperative games, and (re)distributional battles, attention is directed towards the search for unity, political cohesion and solidarity based upon the informed voluntary consent of the people through reflection and reasoned deliberation among individuals with different values, interests, understandings and resources.

Keywords: accountability, democracy, legitimacy, political participation, social control, politics and government 


\section{Introdução: normas para vivermos juntos}

Observando as brincadeiras infantis, não se pode deixar de perceber quanto tempo as crianças passam a discutir sobre o que é o jogo. A quem deve ser permitido jogar? Quais são as regras e quais deveriam ser? O que é justo e o que conta como quebra de regras? Quais são e quais devem ser as consequências de quebrar as regras? Quem pode sancionar as situações de quebra de regras? Quem deve ser autorizado a criar, a interpretar e a alterar regras? Como e por quê?

Por mais de 2000 anos, os estudiosos da política têm lutado com questões semelhantes. Eles exploraram por que os seres humanos constituem comunidades políticas e quais formas de vida coletiva são desejáveis e realizáveis: quem se qualifica como membro de uma comunidade e como eles se organizam e se governam? O que é digno de proteção pública, de acordo com os padrões éticos e normativos de avaliação? Eles examinaram até que ponto a qualidade de vida depende da ordem e da mudança legítimas e perguntaram como a organização política contribui para a coexistência civilizada entre indivíduos com diferentes valores, interesses, entendimentos e recursos, e se as ordens políticas podem ser projetadas para alcançar objetivos substantivos, por quem e como. Além disso, Sólon observou que a hostilidade pode ser reduzida, dando às pessoas poder para eleger representantes e exigindo responsabilidade deles no final de seu mandato (ARISTÓtelES, 1962, p. 124).

Hoje, os estudiosos da política também falam sobre "as regras do jogo" e "jogar pelas regras". Sociedades comprometidas com o governo democrático, a representação e a accountability são cruciais para garantir a legitimidade. Uma parte do credo é que prevalecerá a vontade do povo. As pessoas são o poder constituinte, e uma ordem legítima deve refletir a forma como os cidadãos querem organizar e governar a vida em comum. A distribuição, o exercício e a mudança de poder devem ser explicados e justificados por meio de argumentos fundamentados e contestação pública, e o consentimento informado e voluntário das regras é fundamental. O governado não deve ser submetido a governantes além de seu controle. Os atores são responsáveis pelo que eles fazem e pelo que poderiam ter feito. Ninguém é responsável por coisas que não controla.

A maioria dos analistas contemporâneos sobre governança democrática enfatiza a accountability como um princípio normativo e um mecanismo para garantir a influência dos cidadãos (BOVENS, 2010). Os processos de accountability devem detectar, avaliar e sancionar os desvios dos mandatos autorizados. Eles também são processos políticos de primeira ordem, oferecendo a oportunidade de contestar a 
verdade, a moral e as bases de poder da ordem existente e desenvolver uma nova. ${ }^{2}$ As percepções dos cidadãos sobre os regimes de accountability dependem do desempenho substantivo, da equidade processual e dos arranjos institucionais para explicar, justificar, avaliar e sancionar o comportamento (PÉREZ DURÁN, 2016). Um regime efetivo de accountability democrática depende de três tipos de processos: (a) as rotinas institucionalizadas de instituições de controle parcialmente autônomas com mandato legal, financeiro, gerencial ou de peritos; (b) accountability dentro de uma ordem política constituída; e (c) accountability como parte da (re)constituição de uma ordem.

O foco aqui é o processo de accountability como desafiador da ordem política no contexto europeu e, em particular, relacionado com instituições de nível europeu. Em democracias estabelecidas é comum tomar a ordem existente como estável e perene, em vez de considerar implacavelmente ordens alternativas. As demandas por explicações e justificativas são mais prováveis em ordens políticas instáveis e em momentos críticos. No caso europeu, as crises desencadearam um repensar da ordem política, seus efeitos e a dinâmica da mudança. As pessoas questionam o tipo de comunidade em que querem viver e os processos de accountability se tornam parte de contestações sobre o papel apropriado das instituições e dos atores. Por isso, o recente aumento das demandas por accountability (SCHMITTER, 2004; Gustavsson; Karlsson; Persson, 2009; Borowiak, 2011; Pollitt; Hupe, 2011; SCHILleMANNS, 2013; BovenS; GoOdIN; SCHILleMANS, 2014; WrIGHT, 2015; OLSEN, 2017).

As demandas por accountability podem ser um sinal de que uma democracia funciona bem. No entanto, um aumento nas demandas por accountability pode desafiar a ordem política e sinaliza que as coisas não funcionam bem. Há descontentamento com a ordem política e não apenas com eventos específicos, decisores ou instituições. As demandas por accountability são então desencadeadas por desvios percebidos de uma ordem política? Ou são parte de uma contestação sobre o que constitui uma ordem legítima? As discussões teóricas contemporâneas sobre accountability são incorporadas principalmente nas concepções de governança

\footnotetext{
${ }^{2}$ Uma ordem política é um arranjo institucional que prescreve quem pode legitimamente tomar decisões aplicáveis a toda a comunidade e quem é responsável e pode ser responsabilizado. Uma instituição é uma coleção relativamente duradoura de regras e práticas organizadas, incorporadas em estruturas de significado e recursos. As instituições criam ordem e mudança ordenada. Elas definem maneiras legítimas de organizar o governo e ações apropriadas para diferentes papéis em vários contextos, por exemplo, que tipo de comportamento pode ser esperado de diferentes detentores de cargos públicos. As instituições mudam rotineiramente, mas não se adaptam automaticamente a reformas intencionais ou mudanças ambientais. Elas são relativamente invariantes diante do volume de negócios dos indivíduos e relativamente resilientes às preferências idiossincráticas e às expectativas dos indivíduos e à mudança das circunstâncias externas (MARCH; OLSEN, 1984, 1989, 2006).
} 
na teoria do principal-agent, e considero que os desenvolvimentos europeus convidam ao reexame dessas premissas. Eu argumento que as transformações europeias oferecem uma oportunidade para revisar questões fundamentais sobre as relações entre organização política e convivência civilizada, questões difíceis de observar em contextos estáveis.

\section{Abordagens principal-agent: controle e conformidade}

As concepções mainstream de accountability são incorporadas em atores de governança - uma família de modelos centrados no ator abordando preocupações relacionadas e compartilhando alguns pressupostos, em vez de uma única e abrangente teoria (GAILMARD, 2014). De acordo com a afirmação de Dahl e Lindblom (1963, p. 273), o "primeiro problema da política" é como os cidadãos podem evitar que os governantes se tornem tiranos. As abordagens de principalagent concebem a accountability como agents responsáveis pelo monitoramento e controle alcançando a conformidade e implementando as preferências do principal. O desafio é estabelecer a compreensão causal e atribuir responsabilidades, punir o comportamento não autorizado e recompensar a conformidade, aprender com os sucessos e falhas e proteger e melhorar a ordem existente.

O papel atribuído ao cálculo racional e ao controle social baseia-se em suposições sobre uma estrutura de autoridade pré-determinada com relações diádicas entre principals e agents, identificando-os e delimitando o que eles podem fazer. Os aspectos fundamentais da ordem - organização política, associação e atores - são tratados como exógenos aos processos estudados. A política envolve principalmente aqueles que tomam decisões e aqueles cujos interesses são atendidos. Os agents agem em nome de, e são responsáveis por, um principal. Os principals e os agents tomam decisões que afetam um ao outro e estão associados por meio da conveniência e de jogos não cooperativos. Eles têm talentos pré-determinados e preferências conflitantes. Os agentes possuem conhecimentos e informações superiores, são oportunistas e não podem ser confiáveis. Os principals definem critérios de sucesso e incentivos de controle para induzir o comportamento desejado. Eles monitoram e avaliam o desempenho dos agentes e punem o comportamento não autorizado. A natureza humana é universal e inflexível. Todos os atores são significativos, racionais, autointeressados e incentivados, calculando a utilidade esperada das alternativas disponíveis. Os atores relevantes são mobilizados em todo o processo estudado. A mudança institucional ocorre por meio de escolhas deliberadas feitas pelo principal como meio para alcançar os resultados desejados. Os contratos são constituídos e alterados através das escolhas racionais de atores individuais. 
Com base na crença de que a democracia representativa (parlamentar) é a melhor forma de autogoverno popular, os agentes são assumidos como responsáveis perante as pessoas por meio de mecanismos eleitorais, escrutínio legislativo e hierarquia político-administrativa. A vontade é formada e expressa através de contestações públicas e eleições competitivas. As decisões autorizadas são tomadas pelo legislador. As decisões são preparadas, implementadas e executadas pelo executivo e pela administração pública (STRøM, 2000; STRøM; MüLLER; BERGMAN, 2003; GOODIN, 2008; GAILMARD, 2014).

Os estudos empíricos, no entanto, mostram que nem sempre os principals e nem os agents cumprem seus papéis (SCHILLEMANS; BusUIOC, 2015). Há também uma necessidade de tornar o pensamento dominante mais compatível com estudos comportamentais da organização político-administrativa (CARPENTER; Krause, 2015; MaggetTI; Papadopoulos, 2016; Olsen, 2017). Considero que as abordagens comuns exageram a importância da racionalidade humana e controlam e subestimam a importância da complexidade, conflito e dinâmica das democracias modernas. Eu argumento que os processos de accountability na Europa fazem parte do desenvolvimento de uma nova ordem política e que é frutífero explorar a dinâmica da accountability como desafiadora da ordem existente. Assim, ofereço uma abordagem institucional que amplia a perspectiva da accountability, tratando mais os aspectos da organização política, da associação e da agência como endógenos aos processos de accountability. ${ }^{3}$ Os regimes de accountability fazem parte de um arranjo institucional para preservar a ordem e a continuidade e também para criar dinâmicas de mudanças. Os processos de accountability ocorrem dentro de ordens estabelecidas e não resolvidas, e elas afetam e são afetadas pelas ordens existentes.

\section{Demandas de accountability desafiadoras da ordem}

Accountability requer decisores identificáveis. No entanto, é difícil para as democracias formularem relações de autoridade claras, consistentes e estáveis e padrões normativos a partir dos quais os atores possam ser responsabilizados. A incerteza, a ambiguidade e o controle limitado são intrínsecos à vida política. Os processos de accountability envolvem blame games e gerenciamento de imagens; discussões racionais e deliberações relacionadas ao que foi feito, o que poderia ter sido feito, se o que foi feito é aceitável; bem como o desenvolvimento de critérios

\footnotetext{
${ }^{3}$ O estudo das instituições tem sido um pilar fundador da Ciência Política (RHOdES; BINDER; RockMAN, 2006), mas a revolução comportamental deu prioridade aos pré-requisitos socioeconômicos para a ordem democrática, em oposição às abordagens institucionais formais-legais dominantes (DAHL, 1963, p. 82 -83).
} 
para avaliação de desempenho, explicações e justificativas. A probabilidade de demandas de accountability depende das bases institucionais, sociais e comportamentais da ordem política, todas endógenas à democracia.

Organização e as bases institucionais da ordem. A autoridade e os arranjos de poder de uma ordem política tornam mais ou menos claro quem são os principals e os agents legítimos. As democracias modernas são políticas compostas com diferenciação institucional e uma combinação precária de princípios normativos e organizacionais (WEBER, 1970, p. 123). Em sociedades polarizadas, as decisões da maioria criam conflitos se as instituições não protegerem as minorias e reduzirem o descontentamento à "insatisfação suportável" (HALL, 2004, p. 138). As eleições, o governo da maioria e a hierarquia não são as únicas fontes de legitimidade. Os cidadãos autorizam várias instituições a agir em seu nome. Existe uma confiança variável na regra da maioria, comando hierárquico, regras legais, negociação corporativa, mercados e sistemas de preços, expertise, tradições, movimentos sociais, sociedade civil e referendos.

Associação e base social da ordem. Isso se refere a quem constitui o povo que deve governar a si próprio e em nome de quem as autoridades agem-seus modos de convivência, moral, confiança e sentimento de pertencimento. As pessoas nas democracias modernas não são "nem comunidades harmoniosamente unificadas, nem meras coleções de indivíduos" (HERzoG, 1989, p. 206). O que, então, une os indivíduos e os mantêm separados e quão profundamente dividida é a sociedade (GLAZER, 2010)? Como são os deveres e os direitos dos indivíduos em relação à comunidade, e os da comunidade em relação aos indivíduos, e como os recursos são distribuídos?

Agência e a base comportamental da ordem. As concepções de accountability dependem de ideias sobre quem governa e como eles realmente usam, e devem usar, seu poder. Uma abordagem institucional sustenta que a natureza humana é complexa e dinâmica. O egoísmo racional é uma mentalidade entre várias (GUTMANN; THOMPSON, 2010), com legitimidade variável. Os atores podem ser orientados para objetivos e incentivados. Eles podem seguir uma lógica consequencial e calcular a utilidade para empreendimentos menores ou maiores. Ou podem ser portadores de cargos governamentais, portadores de rotinas mentais e comportamentais atendendo funções sociais e seguindo uma lógica interna de adequação derivada de identidades relacionadas a várias coletividades (MARCH; OLSEN, 1989). Os atores podem ou não exercer autocontrole. Eles podem contrariar ou explorar as divisões existentes, encontrar respostas unificadoras e construir comunidade, ou promover a polarização prejudicial ao tecido social. 
Chamar os governantes a prestar contas e sancioná-los requer recursos, e é importante reconhecer as limitações dos poderes dos cidadãos (SCHATTSCHNEIDER, 1960, p. 140-141). Não podemos esperar uma atenção contínua à accountability relacionada à ordem política. Nas democracias liberais, a política é um espetáculo no grande circo da vida (DAHL, 1961, p. 305) e as democracias precisam permitir aos cidadãos responsabilizar os governantes sem a contínua participação dos primeiros (OLSEN, 2003, 2010). Participantes e problemas são ativados e desativados ao longo do tempo. A accountability atrai a atenção do público e envolve a mobilização em massa ou passa em grande parte despercebida pelo público. Os cidadãos podem ser passivos, confusos, frustrados e alienados. Ainda assim, sob certas condições, eles assumem o chapéu de Sócrates. Eles pedem aos governantes e aos concidadãos para prestar conta do que eles fazem e por que eles estão fazendo isso (BOURKE; GEUSS, 2009).

Existem bons motivos para prestar contas não só aqueles que atuam em nome de, e com mandato da comunidade, mas todos os atores que afetam profundamente o bem-estar da comunidade. Isso é assim, em particular, em uma era de quase hegemonia de visões empresariais privadas da organização políticoadministrativa, poder público fragmentado e enfraquecido, atores privados envolvidos na elaboração e implementação de políticas públicas e contratos incompletos sobre como as decisões devem ser compreendidas e aplicadas em diferentes circunstâncias. Além disso, a antiga ideia de que um cidadão é responsável perante a cidadania por sua atuação como cidadão é reivindicada como estranha às democracias modernas (BoRoWIAK, 2011, p. 93-94). No entanto, o poder do cidadão com a isenção da accountability introduz irresponsabilidade inaceitável no governo democrático (MARCH; OLSEN, 1995, p. 153). Em uma democracia, os cidadãos são portadores de deveres e de direitos. A qualidade democrática depende do quão responsáveis são os cidadãos pela compreensão dos padrões normativos que aplicam, das suas decisões e da participação políticocívica, inclusive em um período com proliferação de referendos.

A política é frequentemente usada como sinônimo de escolha e os eventos são considerados como resultado de decisões. Os processos de accountability, no entanto, envolvem a tomada de decisões e a tomada de sentido (OLSEN, 2017, Ch. 5). ${ }^{4}$ As democracias são arranjos para desenvolver e transmitir crenças

\footnotetext{
${ }^{4}$ Os processos de accountability fazem parte do desenvolvimento institucional. Explicam e justificam o que aconteceu e por que, definem o que é politicamente possível e o que poderia ter sido feito de forma diferente; padrões normativos que prescrevam o que é desejável e como as ações e os eventos são avaliados; recursos que possibilitem pôr em prática palavras e decisões; e adaptabilidade, aprendendo com a experiência e tomando medidas corretivas quando as coisas dão errado (MARCH; OLSEN, 1995).
} 
e identidades democráticas (MARCH; OLSEN, 1995), e os cidadãos tentam criar ordem em suas vidas, incluindo interpretações do que é politicamente necessário, possível e desejável. O motivo crítico, o inquérito, a oposição legítima e a liberdade de expressão e de associação fazem parte de uma tradição europeia. A democracia é uma aposta na possibilidade de que as pessoas aprendam a agir com base na experiência e na razão (DAHL, 1989, p. 192). A inteligência e a melhoria, no entanto, não estão garantidas (MARCH; OLSEN, 1995, p. 206-211; MARCH, 2010). A escolha constitutiva é limitada e moldada por quais modelos são familiares (GYORFI, 2016, p. 23). Novas ordens usam os restos das antigas (TocQUEVILLE, 1955, p. vii). A atenção e os recursos se afastam de perguntas sobre ordem para outros itens priorizados (MARCH; OLSEN, 1983). As demandas se desenvolvem ao longo do tempo como artefatos de uma ecologia de mecanismos de adaptação, como escolha racional, aprendizagem experiencial, imitação, difusão e seleção competitiva - todos imperfeitos (MARCH, 1981).

Como, então, podemos esperar que a ordem política afete os processos de accountability? Uma abordagem institucional sugere que associações políticas com diferentes misturas de unidade e diversidade, confiança e desconfiança e experiências históricas geram diferentes potenciais para demandas de accountability. A história e a cultura compartilhadas podem tornar possível uma ampla agenda política ou fazer com que os cidadãos lidem com a maioria das situações sem interferência governamental. As rotinas institucionais, as ideias, as demandas e os recursos tornam a política mais ou menos capaz de lidar com as divisões e gerar soluções mutuamente entendidas e aceitáveis, afetando também a necessidade de que os governados devam chamar os governantes a prestarem contas de seus atos. A agência política e a influência da opinião pública influenciam quais opções de accountability são realmente usadas.

É provável que os altos graus de satisfação e confiança promovam a passividade popular. É improvável que os governados chamem os governantes para prestar contas se os detentores do poder rotineiramente antecipam o que os cidadãos verão como legítimo, exercitam autorrestrição, permanecem dentro da zona de aceitação dos cidadãos (SIMON, 1957, p. 12) e relatam práticas e resultados para a cidadania. As crises de performance tendem a gerar uma busca de novas alternativas (CYERT; MARCH, 1963). Os constrangimentos, desapontamentos e escândalos são susceptíveis de promover demandas de accountability, uma tendência fortalecida por um alto nível de midiatização da política. E as controvérsias sociais podem dominar a capacidade das instituições políticas para lidar com as divisões, criando indecisão e bloqueio.

Os três regimes estilizados nas rotinas de accountability, a accountability dentro de uma ordem política e a accountability desafiadora da ordem política caem 
em um contínuo de "resolução" (GoodIN, 2012), assumindo diferentes formas de organização política, associação e atores, e políticas que mantêm ou moldam regras, sociedades e indivíduos adequadamente. As rotinas de accountability implicam instituições estabelecidas e profissionais de tempo integral que atuam em estruturas hierárquicas e especializadas. Existem atores identificáveis, linhas de autoridade claras, consistentes e transparentes, e mandatos. Os atores fazem o que deveriam fazer. Eles são programados por meio de um repertório de regras, procedimentos operacionais, padrões e recursos (MARCH; SIMON, 1958; MARCH; SCHULZ; ZHOU, 2000). As questões são descobertas por instituições de vigilância competentes, independentes e imparciais, estabelecendo disputas de acordo com o conhecimento sobre relações entre meios e fins ou regras. Na maioria das vezes, existe pouca necessidade de argumentação pública e contestação. A tarefa é proteger a ordem existente e controlar e disciplinar os agentes indisciplinados. No entanto, em sociedades divididas, em que partes da população desconfiam de instituições e atores de accountability, as rotinas podem, sob algumas condições, desencadear mobilização política, polarização e instabilidade democrática. ${ }^{5}$ Os processos de accountability podem, portanto, ser tanto para manter a ordem quanto para transformá-la. Eles podem envolver a política dentro de uma ordem ou tentam desafiar uma ordem existente e estabelecer uma nova.

A accountability dentro de uma ordem política assume conotação menos conflitiva. É uma normalidade política que contém debate público, contestação partidária e oposição institucionalizada que mantém o governo accountable, mas a atenção é geralmente em eventos únicos, atores e instituições. Quanto mais interdependência, com a premissa de decisão de muitas fontes, mais problemático é identificar as contribuições de atores específicos e sobre o que eles podem legitimamente ser responsabilizados. Os centros de poder parcialmente autônomos, em vez de um único centro dominante, tornam difícil atribuir objetivamente a accountability, abrindo para política e jogos de culpa. O resultado dos processos de accountability depende dos processos pós-evento que podem envolver uma busca pela verdade e aprendizagem, ou drama público por políticos eleitos ou funcionários não eleitos (GRUBE, 2014). A capacidade de um ministro para sobreviver a crises depende do controle da culpa e da intensidade da pressão de responsabilidade dos meios de comunicação de massa e da oposição política (BRÄNDSTRÖM, 2015).

\footnotetext{
${ }^{5}$ Interessante observar tais processos no Brasil. Por exemplo, quando as rotinas institucionais são usadas para investigar, prender e condenar um presidente por corrupção, isso pode ser interpretado por alguns como sinal de um regime de accountability que funciona bem e por outros como abuso de poder. Para esses últimos, as instituições de accountability estão agindo "politicamente" e não de forma imparcial. Elas vão além de seu mandato e ameaçam a democracia e as instituições baseadas na maioria. Há corrupção da democracia em vez de detectar corrupção dentro de uma democracia.
} 
A accountability desafiadora da ordem política é mais provável em contextos institucionais instáveis, períodos de turbulência e situações sem precedentes. Há narrativas críticas da política e da sociedade - reivindicações rivais de verdade, virtude e poder e interpretações concorrentes do que a accountability significa e implica e quais detentores de poder devem ser responsabilizados. As estruturas abertas, como a esfera pública e a sociedade civil, proporcionam espaço para a mobilização política. A accountability é um dos mecanismos por meio dos quais as comunidades desenvolvem, aceitam, aplicam e mudam os princípios normativos e organizacionais para a alocação, uso e controle de poder (OLSEN, 2017).

Todos os três regimes de accountability são importantes nas democracias, mas as rotinas de accountability têm baixa saliência e raramente atraem a atenção dos cientistas políticos. Abordagens principal-agent são mais propensas a dar uma visão de accountability dentro de políticas públicas estabelecidas. No entanto, o contexto histórico-espacial da Europa torna importante explorar o tipo da accountability desafiadora da ordem política, em contextos em que as rotinas institucionais não existem ou são postas de lado. Durante séculos, as concepções de accountability democrática se desenvolveram no contexto do Estado soberano. No entanto, desde a década de 1980, o papel dominante do Estado como uma organização territorial e hierárquica foi atacado tanto da direita como da esquerda e desafiado pela integração européia e pela globalização. ${ }^{6}$ As condições exigidas para instituições democráticas que funcionam bem foram encontradas ausentes no nível internacional (DAHL, 1999, p. 927) e, portanto, era necessário repensar a accountability e o controle popular além do Estado (GRANT; KEOHANE 2005). Agora, uma nova ordem política europeia está se desenvolvendo, mas há desacordo sobre o tipo de ordem que está emergindo, como isso acontecerá e com quais efeitos. É necessário repensar a accountability democrática para além do Estado.

\section{A mudança da ordem política europeia}

Na União Europeia, "a política mais complexa do mundo" (SCHMITTER, 2016, p. 410), demandas de accountability refletem o descontentamento público. No entanto, na comparação internacional, os Estados europeus estão basicamente funcionando bem. Tem sido comum ver a União Europeia como um caso bem sucedido de integração, e a União possui instituições de accountability bastante desenvolvidas

\footnotetext{
${ }^{6}$ A esquerda criticou as contradições, problemas fiscais e estagflação do "Estado de bem-estar capitalista" e seu controle central, dominação burocrática e formas de participação política (OFFE, 1984). A Nova Direita aspirava a reverter o Estado, reduzir o alcance da política e dar primazia à privatização, desregulamentação, terceirização, parcerias público-privadas, mercados e contratos. O principal desenvolvimento foi para uma ordem liberal, um contrato social mais curto e com mais responsabilidade individual (DAHRENDORF, 1988).
} 
(Egeberg, 2006; Bovens; CuRTIn; 'T HART, 2010; Busuioc, 2010; TRONDAL, 2010). O que, então, de acordo com os críticos, é errado e quem é responsável e deve ser chamado a prestar contas?

O desemprego e a pobreza tornam os cidadãos muito frustrados, desiludidos e irritados. Existe o medo do terrorismo, da guerra, da crise econômica, da perda de identidade devido à imigração e eventos climáticos. O mundo é visto como confuso, ameaçador e incontrolável e há preocupações com a legitimidade democrática (SCHMITTER, 2000; ERIKSEN; FosSum, 2012; ChALMERS; JACHTENFUCHS; JOERGES, 2016; FABBRINI, 2016). As demandas de accountability desafiadoras da ordem refletem uma quebra da narrativa dos vencedores da União Europeia. Os acadêmicos afirmam que as crises provocaram "o fim do sonho dos eurocratas" de uma integração funcionalmente dirigida liderada por tecnocratas (CHALMERS; JACHTENFUCHS; JOERGES, 2016). Há retrocessos democráticos em partes da Europa Oriental e Central, abertura a lideranças autoritárias e menor disposição para usar os canais tradicionais de participação democrática (FOA; MoUNCK, 2016). A democracia, o Estado de direito e os direitos humanos estão em perigo, e as respostas da União Europeia têm sido relutantes e inconsistentes (DAWSON; HANLEY, 2016; Kochenov; MAgen; PeCH, 2016).

Segundo as críticas, as autoridades não abordaram efetivamente a raiva e os receios de cidadãos desiludidos que não se beneficiaram da integração europeia e do comércio global, em grande parte dos segmentos menos educados da população. Há discrepâncias entre narrativas oficiais e a realidade que os cidadãos enfrentam, e as autoridades não se adaptaram à opinião pública, nem convenceram o público. Enquanto os meios de comunicação de massa, a internet e as novas tecnologias de comunicação fornecem um fórum para o eurokepticismo e a contestação da política (De Wilde; Trenz, 2012; Statham; TREnZ, 2013), os principais partidos políticos evitam questões internamente divisórias e há pouco entusiasmo pelos referendos. Os resultados dos mecanismos participativos são modestos (BOUSSAGUET, 2016). Os manifestantes são descartados com um uso excessivo de termos como populistas, antieuropeus, fascistas e xenófobos. O sucesso dos movimentos sociais populistas e dos partidos de protesto em eleições e referendos é visto como um perigo para a democracia. No entanto, tais movimentos também podem indicar um mal-estar democrático que requer uma resposta democrática adequada, em vez de sua expulsão da política (NORMAN, 2016; AALBERG et al., 2017).

As autoridades admitem a necessidade de melhorar a accountability democrática da União Europeia e restaurar a legitimidade e a confiança. Na celebração do 60으 aniversário do Tratado de Roma, foi dito, novamente, que a União Europeia está em uma conjuntura crítica. E, na Declaração de Roma, o desejo de uma Europa multiveloz foi subjugado quando a integração foi vista como divisória e uma possível fonte de 
desintegração da União (COUNCIL OF EUROPE, 2017). No entanto, a União Europeia é uma ordem dinâmica multinível com elementos fortes de compartilhamento de poder, padrões normativos contestados e entendimentos causais. Não está claro por qual tipo de ordem os atores são responsáveis e se alguém está no controle e pode legitimamente ser chamado para atender a ordem existente. Os processos de accountability dependem de pontos de vista concorrentes da União Europeia e de parte do poder de renegociação (BOVENS; CURTIN; 'T HART, 2010, p. 11).

Responsável por qual ordem? As demandas de accountability geralmente usam o governo parlamentar como um padrão normativo, e é comum afirmar que os cidadãos esperam recuperar o controle através de instituições supranacionais responsáveis (AyraUtT; SteinMeIER, 2016, p. 11). O Tratado de Lisboa (2009) declarou que a União Europeia deveria ser fundada em democracia representativa, que foi vista como abertura de um novo capítulo da história europeia (PIRIS, 2010). O tratado visava ampliar os poderes e estabelecer uma posição de supervisão mais forte para os parlamentos europeus e dos Estados membros, a fim de reforçar a legitimidade democrática da União Eueropeia (CREMADES; NovAK, 2017, p. 46-49).

Ainda assim, a cidadania europeia é um conceito vago. A accountability parlamentar é "notavelmente fraca" (WEILER, 2012), e as ideias sobre a soberania parlamentar são contestadas (SEDELMEIER, 2012). A identidade coletiva, incorporada na cidadania e definindo um bem comum como a base final da accountability, é equívoca e em fluxo. Os parlamentos nacionais sofrem de um déficit da oposição e só conseguiram parcialmente reforçar a accountability da União Europeia (RAUH;DE WILDE, 2017). O modelo também é problemático para ser aplicado às eleições parlamentares europeias. É difícil para os cidadãos atribuir responsabilidades, chamar os governantes a prestar contas, atribuir elogios e punir ou recompensar atores nas urnas (HOBOLT; TILLEY, 2014). A União Europeia foi projetada para permitir que os decisores políticos evadam o controle popular e a accountability. Não há oposição institucionalizada e arranjos para canalizar o descontentamento e os protestos são fracos. As grandes coalizões, as normas de consenso e a governança baseada em especialistas desmascaram a distinção governo-oposição e, assim, reduzem as motivações e capacidades institucionais para chamar rotineiramente os governantes a prestarem contas de seus atos e se responsabilizarem em público. Os votos dos cidadãos, a política e a formulação de políticas são vagamente articulados (MÉNY, 2012; PAPAdOPOULOS, 2013), e as críticas à política tornam-se necessárias porque a União não consegue integrar a rotina de oposição a políticas públicas e fornecer uma saída para a crítica da ordem (MAIR, 2007, p. 6, 2013, Ch. 4). Juntos, esses fenômenos são parte das razões pelas quais a accountability é profundamente contestada e as demandas de accountability desafiadoras da ordem fazem parte da contestação da ordem política. 
Em vez de relações diádicas entre principals e agents, há redes densas e em evolução de arranjos de accountability, com padrões normativos contraditórios. Não existe uma narrativa unificadora que explique e justifique a ordem existente, nem existe uma visão compartilhada de como a accountability deve ser organizada e legitimada (JACHTENFUCHS; DIEZ; JUNG, 1998). A legitimidade depende de um equilíbrio delicado entre múltiplas ordens, instituições representativas e eleitorados (MICHALSKY; NORMAN, 2016; YURATICH, 2017). Para ser eficaz, a accountability requer cooperação entre fóruns verticais e horizontais - instituições de auditoria, inspetores, comitês de escrutínio, tribunais, provedores de justiça, investigações, formas transnacionais de supervisão parlamentar e meios de comunicação de massa (CRUM; Fossum, 2009; BOVEnS; CURTIN; 'T HART, 2010; BRANDSMA; HeIdBreder; MAStenbroek, 2016; BormanN; Winzen, 2016; Wille, 2016). Os processos de accountability passaram de arenas abertas e democráticas para redes isoladas de especialistas, enfraquecendo a accountability democrática (BRANDSMA; HEIDBREDER; MASTENBROEK, 2016; WILLE, 2016). É incerta a importância de comparações com outras perspectivas normativas. Provavelmente, a proliferação de interações que envolvam accountability e a acumulação de obrigações de accountability e padrões normativos criam mais accountability e menos democracia (PAPADOPOULOS, 2010).

Além disso, a democracia, como princípio de legitimação, fornece orientações limitadas para a organização de uma ordem política. O termo é aberto e problemático quando usado para avaliar arranjos e ações institucionais (KOCHENOV; MAGEN; PECH, 2016). Historicamente, a Europa é um continente onde o significado e as implicações da democracia foram contestados (MüLleR, 2011), e, em uma "era da democracia confusa", é difícil encontrar suas demonstrações no ato de governar (SARTORI, 1987, p. 6 e 86). ${ }^{7}$ A democracia baseia-se na existência de uma política com o demos como o poder constituinte, autorizando os atores a exercitar o poder e a legitimar suas decisões (WEILER, 1996, p. 111). No entanto, a democracia não prescreve fronteiras territoriais precisas, quem se qualifica como cidadão ou quem deve decidir legitimamente quem deve ser incluído. É de ajuda limitada apelar para o princípio de que as pessoas devem decidir quando há conflito sobre se as demonstrações democráticas devem ser fundadas em termos de territorialidade, história, nacionalidade, etnia, compromisso com princípios políticos específicos, ou em termos sujeitos ou afetados pelo governo e leis (GOODIN, 2007; NÄSSTRÖM, 2011; OWEN, 2012; SCHERZ, 2013; KYMLICKA, 2015).

\footnotetext{
${ }^{7}$ No entanto, o colapso da União Soviética e dos regimes comunistas na Europa Central e Oriental foi visto como um triunfo para a democracia e a reunificação europeia (REYKowsKı, 1994), e, em 2001, afirmou-se que "em nenhum momento da história mundial tem havido causa para maior otimismo sobre o futuro da democracia" (DIAMOND, 2001, p. 154).
} 
Quem é responsável pela ordem existente? É menos do que claro o papel que as decisões deliberadas têm nos desenvolvimentos institucionais europeus e a forma como os decisores responsáveis podem ser identificados. Os documentos oficiais da União Europeia refletem a fé na razão e na escolha humana. Os tratados são importantes e o design da ordem política é uma questão de vontade política. O Livro Branco da Comissão Europeia sobre o futuro da Europa assume que "a forma seguirá a função" (EUROPEAN COMMISsion, 2017, p. 15). Ainda assim, todas as organizações têm suas marcas de nascença. Elas são marcadas pelo momento da história em que elas chegam e as ideias e os recursos disponíveis (STINCHCOMBE, 1965), e a legitimidade da União Europeia no momento da sua fundação não se baseou na representação democrática e na accountability (PREUSS, 1996, p. 219; WEILER, 2012, p. 252 e 263). O contexto foi o colapso da República de Weimar, o surgimento de regimes autoritários e a Segunda Guerra Mundial, que desacreditou - em particular na Alemanha - o Estado-nação, a supremacia parlamentar, os referendos, o nacionalismo e as pessoas comuns. As massas foram vistas como agindo emocionalmente, prontas para abandonar modos constitucionais de atividade política em favor de ações descontroladas fora e contra a ordem institucional. A partilha de poder deveria ser garantida por meio do federalismo e do poder presidencial reduzido, enquanto os direitos fundamentais deveriam ser protegidos pelos tribunais. Os referendos foram abolidos para evitar que a democracia fosse eliminada por meios democráticos (KORNHAUSER, 1959; BOROWSKI, 2003; GYORFI, 2016, p. 11). ${ }^{8}$

A escolha do futuro da Europa através da consolidação deliberada de instituições também é problemática (OLSEN, 2007, 2010). Nenhum centro político único pode legitimamente reivindicar representar o povo europeu. Nenhuma autoridade está no controle e governa a União (MAJONE, 2014). As alternativas politicamente viáveis tendem a ser ineficazes, enquanto as mudanças radicais não possuem viabilidade política (SCHARPF, 2015, p. 397). A ordem política da União Europeia e os regimes de accountability não são projetados de acordo com uma única lógica. Existem concepções concorrentes de acordos reais, possíveis e desejáveis, e os processos de mudança foram contestados e ad hoc, por exemplo, à medida que

\footnotetext{
${ }^{8}$ Entre as duas guerras mundiais, havia uma literatura sobre o caos social e intelectual e a decadência ou a morte da civilização ocidental. As normas e a verdade que antes se acreditava serem absolutas, universais e eternas foram declaradas necessitadas de demonstração e prova. Os critérios de prova tornaram-se sujeitos à disputa. Os fundamentos da ordem social e intelectual foram abalados (WIRTH, 1936, p. x-xi). O colapso da República de Weimar foi visto como causado pela subordinação de todas as outras instituições às exigências do capitalismo de mercado (POLANYI, 1957), e um fluxo repentino e grande de novos elementos da população foi percebido pelos antigos residentes como uma ameaça ao seu status e controle, fazendo com que eles respondessem organizando movimentos anti-imigrantes (KORNHAUSER, 1959, p. 147).
} 
novos membros se juntaram à União. A ordem política europeia reflete uma série desordenada, contingente e casual de lutas políticas e não pode ser reduzida a um instrumento de vontade política ou direito moral (WILKINSON, 2013, p. 207-208). Os desenvolvimentos institucionais foram subprodutos de eventos e tentativas de lidar com os problemas mais dramáticos do dia, mais do que uma questão de escolha e uma visão geral (HooghE; MARKs, 2001, p. 36; MÉnY, 2012, p. 159). As relações institucionais foram moldadas em processos policêntricos e abertos com uma ampla gama de possíveis desenvolvimentos. Houve interação entre atores cujos papéis e funções não foram predefinidos por um conceito abrangente de ordem política legítima. Princípios concorrentes de legitimação e forças opostas de integração e desintegração têm sido conduzidos por agentes que foram formados em parte pelo próprio processo (PREUSS, 1996, p. 218). A ordem foi forjada através de processos de interação e conflito (STEPHENSON, 2016). Foram tentados esforços para responsabilizar a Comissão perante o Parlamento Europeu e as agências responsáveis pela Comissão (BOVENS; CURTIN; 'T HART, 2010; BUSUIOC, 2010; WILLE, 2013). O Estado e a nação mostraram uma resiliência considerável, e, como o Projeto de Tratado de Constituição para a Europa de 2004 foi rejeitado nos referendos, "não se pode realisticamente esperar um grande projeto ou grandeza constitucional no nível da UE” (BOVENS; CURTIN; 'T HART, 2010, p. 197).

Accountability desafiadora da ordem. Para os construtores de teoria, a busca persistente da accountability, apesar das dificuldades de validamente estabelecer responsabilidade causal e atribuir crédito e responsabilidade, representa um desafio. Para atores políticos, a incerteza cria um espaço para jogos de culpa. Em uma ordem não institucionalizada, não é surpreendente observar processos de accountability desafiadora de ordem política vívidos e não apenas rotinas de accountability e accountability dentro da ordem estabelecida.

A tensão entre os níveis verticais do governo - construção europeia e a autonomia dos Estados membros - é bem conhecida. Alguns querem uma União cada vez mais estreita entre os povos da Europa e criticam uma erosão percebida e rasteira do projeto europeu. A União Europeia é vista como necessária para lidar com os problemas que enfrenta o continente e é necessária uma maior cooperação, coordenação e integração nas fronteiras nacionais (CREMADES; NOVAK, 2017; JUNCKER, 2017). As autoridades apontam para uma incompatibilidade entre expectativas e capacidades e a necessidade de fortalecer as instituições da União e seus "recursos próprios" (MONTI et al., 2016). Os problemas enfrentados pela União Europeia são atribuídos aos sistemas políticos nacionais e a União precisa responsabilizar os Estados membros pelo cumprimento dos compromissos (EUROPEAN COMMISSION, 2015, p. 9, 2016, 2017, p. 12; COUNCIL OF EUROPE, 2017). 
Outros afirmam que a integração foi muito longe, restringindo a autogovernança nacional e a accountability para os eleitores nacionais e os parlamentos. Os países de Visegrad querem retornar o poder aos Estados membros - Conselho Europeu de 2016. O referendo de Brexit envolveu objeção a eurocratas inexplicáveis em Bruxelas e desacordo sobre quem pertence ao povo. Deixar o processo aos eleitores enfatizou a soberania nacional, a identidade cultural, o controle de fronteiras, a migração e o emprego (НовоLт, 2016). A primeira-ministra Theresa May ativou visões do Parlamento soberano e governo democraticamente responsável. O voto de licença foi interpretado como um mandato para repatriar o poder da Grã-Bretanha em relação a Bruxelas - ou seja, o poder de controlar seus próprios assuntos, incluindo a imigração - e encerrar a jurisdição do Tribunal de Justiça da União Europeia. 0 Primeiro-Ministro evocou a possibilidade da destruição da União Europeia (HM GoVERNMENT, 2017). No entanto, o Brexit ilustra a incerteza quanto à evolução da opinião pública sobre a União Europeia e da forma como os políticos respondem (RENWICK, 2017). Os processos, os resultados e as consequências a longo prazo são difíceis de prever, inclusive se o Brexit realmente acontecerá.

As demandas de accountability desafiadoras da ordem política também refletem críticas das relações horizontais entre, por um lado, as pessoas e representantes democraticamente eleitos e, por outro lado, mercados, tribunais, agências especializadas e executivos. As queixas são duplas. Elas estão relacionadas a um equilíbrio de poder interinstitucional em mudança e também a discrepâncias entre autorrepresentações institucionais e práticas. As instituições são criticadas por navegar sob falsas cores alegando que são governadas pela concorrência e imperativos de mercado, pela interpretação imparcial do direito, por decisões puramente baseadas no conhecimento ou por necessidades funcionais, enquanto que, na prática, possuem considerável poder discricionário para tomar decisões em benefício de uns mais do que outros.

Mercados: uma crítica fundamental é que a constitucionalização dos direitos econômicos e múltiplos veto-points políticos exigem um amplo acordo que restrinja a capacidade democrática (europeia e doméstica) de lidar com os problemas do capitalismo global e o aumento da desigualdade. A construção do mercado é um aspecto fundamental da integração europeia, e o domínio da concorrência no mercado aumentou. Mas também há o impacto de atores econômicos engenhosos, mudando o equilíbrio de poder entre as autoridades do capital, do trabalho e autoridades políticas (SCHARPF, 2015, 2016). O domínio da tomada de decisão democrática e da accountability diminuiu. No entanto, o poder político também tem sido usado para proteger (alguns) atores econômicos da intervenção política (STREECK, 2015). A concorrência de mercado como metaprincípio ideológico impede que o governo local intervenha nos mercados de forma a distorcer a concorrência (NYBERG, 2015). 
Tribunais: a regra representativa é vista como limitada pelo ativismo judicial e interpretações teleológicas dos tratados. É necessária a flexibilidade para chegar a acordos entre Estados membros (PIRIS, 2010, p. 202), e os tratados conferem ampla margem de apreciação aos juízes (MAGEN, 2016, p. 1051). O tribunal usurpou o poder e priorizou a concorrência do mercado e as liberdades econômicas, capacitando grandes atores do mercado e legisladores restritivos (STONE SWEET, 2004; WILKINSON, 2013; Joerges; KREUder-Sonnen, 2017; MenÉndeZ, 2017). O ethos profissional dos juízes foi redefinido (PAPADOPOULOS, 2013, p. 198), e o constitucionalismo se tornou uma ideologia abrangente. A possibilidade de governar por advogados e não pela lei (KRATOCHWIL, 2009) cria uma necessidade de reequilíbrio das relações de poder político-judicial, com desconstitucionalidade de direitos econômicos e a facilitação e legitimação do domínio da maioria (BARTL, 2015; SCHARPF, 2016).

Agências de vigilância: as rotinas de accountability dependem de agências de vigilância habilitadas colocadas fora das hierarquias ministeriais e à distância da política e do controle eleitoral direto (ThATCHER; STONE SWEET, 2002; Busuioc; GroenleER; TRONDAL, 2012) - arranjos baseados em retóricas apolíticas ou antipolíticas que enfatizam as necessidades funcionais e negam os conflitos. A Comissão Europeia afirma salvaguardar tratados e interesses europeus. O Banco Central Europeu obedece à lei, não a políticos. Fazer suposições sobre um povo unificado, um interesse comum preciso ou regras claras dá primazia para encontrar meios eficientes, uma tarefa geralmente deixada aos especialistas. No entanto, a Comissão e o Banco tomam decisões redistributivas e os críticos argumentam que o fortalecimento de instituições não majoritárias e atores não eleitos favorece certos grupos em relação a outros, reduz a accountability direta aos cidadãos e coloca dificuldades para a responsabilidade parlamentar (THATCHER; STONE SWEET, 2002, p. 18). O mandato do Banco Central Europeu, combinado com uma transparência limitada e dando primazia à eficiência, desvia a atenção de suas bases normativas e de poder, possivelmente "implicações preocupantes para a legitimidade democrática e a accountability" (MCNAMARA, 2002, p. 49; BARTL, 2015; WHITE, 2015; CURTIN, 2017). Também pode ser fútil e contraproducente tentar despolitizar questões redistributivas ao encobri-las como regulação apolítica e isolá-las da accountability politico-legal (BÖRZEL, 2016, p. 25). ${ }^{9}$

\footnotetext{
${ }^{9}$ Do mesmo modo, a New Public Management é muitas vezes enquadrada como modernização apolítica - melhorando o desempenho, reduzindo "burocracia excessiva" e promovendo a eficiência e a economia também quando ela afeta o equilíbrio interinstitucional de poder. Princípios de accountability são corporativogerenciais e celebram autonomia de gerenciamento, parcerias público-privadas e cidadãos concebidos como clientes. Diminuir ou esmagar a burocracia funciona como uma retórica útil. Mas a existência de múltiplos públicos torna difícil conciliar a accountability com base na hierarquia do governo, padrões profissionais e visões de mercado (WIESEL; MODELL; MoLL, 2011), e as reformas administrativas não necessariamente melhoram a accountability e a legitimidade (CHRISTENSEN; LAEGREID, 2017), nem a autonomia formal-legal assegura a independência política (ENNSER-JEDENASTIK, 2016). É possível que a reinvenção do governo implique a redefinição da democracia (PIERRE, 2009).
} 
Executivos: a crise da dívida e os esforços para salvar o euro e tranquilizar os mercados de capitais são pensados para gerar o domínio do Executivo. 0 novo regime de governança econômica tem sido criticado por causar déficits de accountability, limitando o papel dos parlamentos e prejudicando a legitimidade democrática. A governança econômica pós-crise partiu dos mecanismos disponíveis de accountability político-legal. A democracia foi marginalizada por uma retórica de emergência, ameaças existenciais e necessidades econômicas, mesmo quando as questões envolvem conflitos distributivos profundos, desenvolvimentos em particular afetando os países devedores (MENÉNDEZ, 2015; PAPADOPOULOS, 2013; DAWSON, 2015; WhITE, 2015; SCHARPF, 2015; JOERGES, 2016; NAERT, 2016).

A visão de mundo das vozes críticas e seu desejo de fortalecer a política democrática e a accountability não são, no entanto, universais. Houve opiniões concorrentes sobre se existe um déficit democrático na União Europeia e se a União é e deve ser um projeto democrático (MAJONE, 1998; MORAVCSIK, 2004; FøLLESDAL; HIX, 2006). Contestações sobre as relações adequadas entre cidadãos, representantes eleitos, mercados, tribunais, peritos e executivos são uma parte importante do discurso liberal (PÉREZ-DíAz, 2014), e há chamados para "despolitizar a democracia", tirando decisões da influência direta de representantes eleitos e paixões populares (PETTIT, 2004). Os liberais do mercado favorecem uma ordem baseada na liberdade individual, com os cidadãos resolvendo problemas em mercados autorreguladores e na sociedade civil sem a intervenção de qualquer autoridade pública (MISES INSTITUTE, 2016). ${ }^{10}$ Os atores políticos vinculados através de regras fornecem uma solução para problemas de credibilidade (KYDLAND; PRESCOTT, 1977), e a competição entre os partidos políticos deve ser alcançada por meio de mecanismos de mercado (ISSACHAROFF; PILDES, 1998). As restrições constitucionais e os tribunais independentes são bem-vindos como partes integrantes de uma concepção de democracia superior ao governo majoritário, e os tribunais constitucionais são considerados a manifestação institucional e o símbolo de uma nova concepção da democracia (GYORFI, 2016, p. 22 e 33). As instituições independentes produtoras de fato são importantes, e as instituições com experiência funcional, como o Banco Central Europeu, são uma pedra angular de uma arquitetura institucional legítima (ToWfIGH, 2016). Enquanto outros estavam paralisados pela crise, o Banco Central Europeu demonstrou uma "capacidade de resposta rápida e eficaz para evitar um colapso da zona do euro" (KRAMPF, 2016, p. 467). Finalmente, à liderança executiva é tradicionalmente dada prioridade durante as crises.

\footnotetext{
${ }^{10} \mathrm{Na}$ economia, "é justo procurar o seu próprio interesse, esperando que outros busquem os seus". Nada distingue os economistas tanto quanto sua crença no sistema de mercado. Uma dificuldade perene é a incapacidade de verificar o quanto da confiança na forma como os mercados funcionam é fé e quanto é análise e observação (SCHELLING, 1981, p. 39, 59).
} 
As demandas de accountability desafiadoras da União Europeia fizeram parte dos esforços para encontrar respostas viáveis às questões de quem e o que constituirá a Europa e como desenvolver instituições políticas legítimas para governar. Houve um desenvolvimento de uma ordem política dominada por Estados-Nação para uma ordem com instituições cada vez mais fortes no plano europeu. Esse desenvolvimento não assumiu a forma de uma ordem para ser substituída por outra baseada em princípios normativos e organizacionais completamente diferentes. Em vez disso, envolveu o reequilíbrio basicamente dos princípios normativos e organizacionais legítimos. Também está longe de ser óbvio como a accountability democrática pode ser salvaguardada quando a governança está inserida em redes em todos os níveis de governo, esferas institucionais e domínios público-privados, e baseada em parceria informal e diálogo em vez de relações de controle hierárquico e de controle formal (MICHELS; MEIJER, 2008; KLIJN; KoPPENJAN, 2014).

A União Europeia pode desenvolver-se em diferentes direções. Alguns querem deixar a União Europeia ou devolver o poder aos Estados membros. Outros estão desapontados com o desempenho atual da União e reduziram seu apoio político à atual liderança. No entanto, aumentaram o seu apoio à continuação da integração, com mercados em bom funcionamento e um papel mais forte para as políticas democráticas na luta contra as desigualdades geradas pelo mercado (SIMPSON; LOVELESS, 2017). Alguns prescrevem um tipo de New Deal - criando resultados mais justos, reequilibrando as liberdades de mercado e a segurança social para contrariar a redistribuição regressiva, que aumenta a desigualdade social entre os Estados membros e dentro deles (ORGANIZATION FOR ECONOMIC COOPERATION AND DEVELOPMENT, 2015; BÖRZEL, 2016). Outros prescrevem uma Nova Narrativa. Explicações e justificativas antigas não são convincentes. É necessária uma visão europeia que expresse propósito coletivo, identidade e unidade, facilitando a divisão de poderes e responsabilidades e explicando aos cidadãos o que a União Europeia faz por eles (BATTISTA; SETARI; RosSIGNOL, 2014; COMISSÃo EUROPEIA, 2017, p. 22). ${ }^{11}$

Os desenvolvimentos europeus levantam questões sobre as possibilidades e limitações para influenciar a ordem e a mudança políticas por meio de demandas de accountability democrática. Esses processos envolvem dois desafios: primeiro, como efetivamente responsabilizar os detentores de poder; e, em segundo lugar, e menos atendido, como evitar a responsabilização dos detentores de poder por

\footnotetext{
${ }^{11}$ No contexto de falsas notícias e fatos alternativos, é interessante ler o conselho de Loewenstein (LOEWENSTEIN, 1952, p. 63): "Na Europa, a arte do aconselhamento em relações públicas ainda está em sua infância. Consequentemente, a disseminação da propaganda é intermitente, ineficaz, desorganizada e muitas vezes desprovida de habilidade psicológica. Uma equipe contratada de especialistas em publicidade americana, com o hábito de vender ideias e bens para o consumidor, poderia fazer maravilhas".
} 
coisas que não controlam, o que reduz os níveis de confiança e legitimidade. Os desenvolvimentos levantam questões sobre como entendemos a ordem democrática política relacionadas à forma como o poder é, pode ser, e deve ser exercido e controlado e os propósitos adequados, metas dignas e formas legítimas de persegui-los (GoodıN, 2009, p. 6). Essas questões são particularmente importantes em uma época em que a resiliência da democracia ocidental está sendo testada (COUNCIL OF EUROPE, 2017), e a retórica hegemônica ocidental sobre o liberalismo e o secularismo deve ser explicada e justificada porque "a maioria da população mundial manifestamente não está convencida por qualquer um dos dois" (DRYZEK; HONIG; PHILLIPS, 2006, p. 25).

\section{De volta às raízes: tensões irreversíveis e busca da unidade}

A Europa está em transição e é comum ver a integração europeia como sui generis. No entanto, a dinâmica assemelha-se aos esforços históricos da construção do Estado, da construção da nação e da construção do caráter individual, bem como processos semelhantes observados nos Estados-Nação emergentes atuais (VON BILLERBECK, 2017). Por conseguinte, existem boas razões para não exagerar a singularidade da integração europeia, mas sim ligar as transformações europeias às ideias teóricas sobre política democrática e accountability e remeter o discurso da Ciência Política de volta às suas raízes. Em vez de pedir uma nova ciência da política para uma nova sociedade (TocaUEVILLE, 1945, p. 7), considero que a nossa compreensão do político é facilitada pela conscientização da abordagem histórica da disciplina sobre tensões insolúveis e atos de equilíbrio relacionados às condições prévias para mecanismos civilizados de governança e convivência.

Uma abordagem institucional volta à ideia antiga de que a tarefa dos estudiosos da política é discutir a melhor ordem política absoluta e o que é realizável em contextos locais específicos (ARISTóTELES, 1962, p. 149). Essa aspiração é amplamente consistente com as exigências de que a Ciência Política desenvolva uma teoria política mais política, centrando em questões institucionais, uma vez que elas são privilegiadas como a principal agenda da teoria política normativa (WALDRON, 2016); retorne ao político (Mouffe, 2005); contrarie uma cultura profundamente antipolítica (HAY; STOKER, 2009); leve em consideração as realidades dos Estados administrativos modernos (RUBIN, 2005); e ultrapasse "uma noção completamente artificial de democracia forjada por advogados com base em ideias filosóficas do século XVIII" (DUVERGER, 1964, p. 423) - em outras palavras, que, em vez de começar com "os elevados ideais da teoria democrática clássica" assumindo decisões racionais e cidadãos plenamente informados, os cientistas políticos devem estudar como as pessoas realmente agem e fazem escolhas (DALTON; KLINGEMANN, 2007, p. 6). 
Uma premissa básica para o meu argumento é que as democracias modernas vivem com conflitos não resolvidos (CYERT; MARCH, 1963, p. 117-118). As sociedades concordam com valores gerais e vagos, mas discordam de como esses valores devem ser interpretados e aplicados. Os processos de accountability desafiadores da ordem estão ligados a tensões políticas e a ações de equilíbrio irresistíveis, algumas incorporadas à linguagem da disciplina. Os termos-chave são dinâmicos e contestados, não fixos e acordados (BALL; FARR; HANSON, 1989), e seu poder simbólico e emotivo às vezes é maior do que seu poder analítico. Concepções e limites do político mudam ao longo do tempo (MAIER, 1987). A política é vista como a arte nobre do governo baseada na razão e na justiça e também como uma atividade depravada ligada à razão do Estado e buscando o domínio por todos os meios disponíveis (VIROLI, 1992), um uso pejorativo do termo, muitas vezes ligado a Maquiavel (1513/1532).

Sem negar a importância dos interesses contundentes, das lutas de poder, do comportamento estratégico, dos jogos não cooperativos e das batalhas (re) distributivas, existem também outras vertentes do pensamento político. A política democrática é idealmente uma maneira de governar sociedades divididas sem violência indevida (CRICK, 1982, p. 33). As democracias legitimaram o direito de discordar (COUNCIL OF EUROPE, 2017). Elas institucionalizam oposição e competição por posições de poder, definem regras de contestação e delimitam a área de contestação política. Elas fornecem pontos de vista para desacordo ao mesmo tempo em que suprimem as divisões e ajudam a desenvolver a solidariedade (Wolin, 1960, p. 83; DUVERGER, 1966, p. 163-165). Uma crença democrática é que o conflito se transforme em cooperação através da participação do cidadão, da deliberação pública e da educação cívica (BARBER, 1984, p. 135). No entanto, as democracias podem não conseguir consentimento voluntário devido a capacidades político-institucionais inadequadas, antagonismos na sociedade ou atores que não são motivados ou capazes de construir ou manter a unidade. Provavelmente, a política democrática funciona melhor em sociedades que têm algo entre harmonia perfeita e relações antagônicas entre amigos e inimigos (SCHMITT, 1927).

A perspectiva democrática vai além da agregação de preferências individuais predeterminadas. É uma busca por unidade, coesão política e solidariedade, com base no consentimento informado e voluntário das pessoas por meio da reflexão e da deliberação fundamentada. Há uma busca e construção e afirmação de instituições legítimas, associações e atores que assumem uma disposição e uma capacidade para construir e manter propósito compartilhado e fidelidade a uma ordem política, apesar das muitas forças que trabalham para criar divisão. "A política está eternamente preocupada com a conquista da unidade da diversidade" (WHEELER, 1975, p. 4), e a quintessência da política democrática é a construção 
e reconstrução de nossas vidas conjuntamente, tornando possível a ordem e a convivência civilizada (WILDAVSKY, 1987, p. 5). Um dilema básico é como conciliar a concorrência e a cooperação, criar uma regra comum em meio à diversidade, assegurar a ação coletiva e continuar a ser uma comunidade, mantendo a liberdade e a influência individuais (WOLIN, 1960, p. 61-62; LIPSET; ROKKAN, 1967; MILL, 1977, p. 58; Perry, 1988, p. 181-182; MARCH; OlSEN, 1976, 1989, p. 118; SELZNICK, 1992, p. 369; FILGUEIRAS, 2016).

As democracias equilibram a crença na onipotência do povo com uma desconfiança generalizada nas pessoas. Os cidadãos são vistos como tendo a capacidade racional, mas também como sendo mal informados, desvinculados, crédulos e motivados por emoções. Considerando que o povo é "a única fonte legítima de poder", não deve ter um papel muito ativo devido ao "perigo de perturbar a tranqüilidade pública", com forte interesse pelas paixões públicas. "O governo é instituído porque as paixões dos homens não estarão em conformidade com os ditames da razão e da justiça sem restrições" (HAMILTON; JAY; MADISON, 1964, p. 43, p. 117-120). Sem regras, os humanos vão lutar - essa é a sua natureza (BRENNAN; BUCHANAN, 1985, p. ix, p. 3) -, e na esfera política o lado menos louvável da natureza humana sobe à superfície. O cidadão típico "cai para um nível mais baixo de desempenho mental assim que ele entra no campo político (...) Ele se torna um primitivo novamente. Seu pensamento se torna associativo e afetivo" (SCHUMPETER, 1994, p. 262).

As interpretações racionais são baseadas em um certo grau de relativismo político. Não existe um bem comum verificável objetivamente que as pessoas possam conhecer. A verdade política, os objetivos e os valores formados por meio da discussão gratuita e da controvérsia partidária são tentativos e contestados (HoY, 1968, p. 2; KELSEN, 1955, p. 2 e 38). ${ }^{12}$ As democracias fornecem um forte apoio normativo para linhas claras de autoridade e accountability, regras e objetivos, e um culto de eficiência (SELZNICK, 1957, p. 135) enfatiza meios neutros e efetivos e negligencia a reflexão sobre fins dignos. No entanto, as questões fundamentais raramente são totalmente resolvidas e incorporadas em uma constituição. As instituições governamentais criam alguma ordem e previsibilidade e conseguem objetivos. Ainda assim, há tensões duradouras entre centralização e concentração de poder em um centro soberano e protegem a autonomia das instituições e asseguram controles e contrapesos. Como todas as formas de organização política, a integração europeia envolve a interação entre as dependências mútuas do todo e a independência das partes. Hobbes (1651) enfatizou a necessidade de centralizar

\footnotetext{
${ }^{12}$ Existem abordagens concorrentes. Populismo e tecnocracia afirmam ser capazes de identificar e implementar soluções objetivas que sejam boas para toda a sociedade, com base no conhecimento sobre a autêntica vontade das pessoas ou conhecimentos técnicos (CARAMANI, 2017).
} 
o poder, Montesquieu (1748), a necessidade de equilibrar os poderes. No entanto, esforços para se integrar em uma ordem política competem com os esforços para defender a autonomia das unidades componentes (CRICK, 1982, p. 142; RoKKAN; URWIN, 1983, p. 14; BRUNSSON; OLSEN, 1998; OLSEN, 2007, p. 22, 2009). Todas as ordens políticas enfrentam a questão de quais formas de integração seus componentes podem tolerar e quais formas de diversidade sua ordem pode tolerar (OLSEN, 2007, p. 24).

Existem também concepções concorrentes sobre se as instituições políticas, as comunidades e os indivíduos são, ou deveriam ser, sujeitos de controle democrático, e desacordos sobre o que a justiça e a racionalidade significam e implicam e qual definição de justiça e racionalidade se aplicará (MACINTYRE, 1988). A crença na capacidade do governo de manter a "ordem na terra" (TocoueVILLE, 1955, p. 69) varia ao longo do tempo e entre as ordens políticas. E a legislação como uma ferramenta de regra da maioria compete com a lei como expressão de verdade e justiça (SABINE, 1937, p. 19; BERMAN, 1983). O vencedor do cargo de governante não garante a capacidade real de comando e controle da vontade. O número de votos e a autoridade pública não minimizam todos os outros recursos. $\mathrm{O}$ governo democrata compete com centros de poder baseados em recursos econômicos, religiosos, militares, organizacionais, tecnológicos e profissionais, e as autoridades públicas precisam de apoio de grupos que controlam recursos relevantes (ROKKAN, 1966; Weber, 1978, p. 1164; Ferguson; MANSBACH, 1996).

É difícil combinar qualidade representativa e liderança executiva efetiva, e equilibrar a necessidade de julgamento perito e independência com controle democrático é um problema perene (DAHL, 1999, p. 928). ${ }^{13}$ Para fazer as coisas, as democracias exigem uma administração pública composta por profissionais governados por um ethos de ofício, separando aqueles que tomam decisões e aqueles que se beneficiam delas (BENDIX, 1962, p. 483; MILL, 1962, p. 111-114; WEBER, 1978, Ch. XI; RothSTEIN, 2011). A elaboração de políticas não pode, contudo, ser confiada aos guardiões (DAHL, 1989). A usurpação de poder pelos burocratas é um risco sempre presente (BENDIX, 1962, p. 486; WEBER, 1978, p. 1393). Além disso, as demandas colocadas a funcionários são muitas vezes além das capacidades de seus órgãos, uma vez que as democracias demandam serviços públicos sem fornecer os recursos necessários para implementá-Ios (MARCH; OLSEN, 1995, p. 134-135).

O político é uma esfera de sociedade parcialmente autônoma que lida com o que diz respeito a uma comunidade como um todo (Wolın, 1960, p. 434). As democracias valorizam a vida privada ao lado da vida pública, e a política e a

\footnotetext{
${ }^{13}$ Diamond (1990) explora tensões, paradoxos e contradições inerentes à governança democrática: conflitoconsenso, representatividade/responsabilidade-governabilidade e consentimento-eficácia.
} 
sociedade são esferas de pensamento e ação parcialmente interdependentes, parcialmente autônomas (BENDIX, 1962, p. 487 e 489). O equilíbrio adequado entre a política e a sociedade é comumente contestado. As democracias se debatem sobre a melhor maneira de proteger o domínio privado da intervenção política e o domínio público da intervenção privada, mas é difícil localizar exatamente os limites do político. As democracias precisam conciliar ideias sobre o povo soberano e o indivíduo soberano, mas não há um relato incontestável sobre os poderes relativos das legislaturas em relação às famílias, igrejas, sindicatos, associações empresariais ou indivíduos (CRICK, 1982, p. 170; LEVER, 2009, p. 215).

As democracias dependem da qualidade de seus cidadãos e de como eles se associam. O debate europeu sobre a falta do demos (PREUSS, 1996, p. 210) ativa a velha questão sobre o que uma população que deveria governar deve compartilhar para se informar e constituir um consentimento voluntário possível. De acordo com Durkheim (1969, p. 25), uma sociedade não pode manter-se unida, a menos que exista entre seus membros uma certa comunidade intelectual e moral. John Stuart Mill afirmou que "as instituições livres são quase impossíveis em um país composto por diferentes nacionalidades" (MILL, 1962, p. 309). No entanto, "os europeus sempre tiveram que trabalhar duro para encontrar raízes comuns e a origem da unidade em seu passado problemático" (WARD-PERKINS, 2005, p. 174). Não obstante a afirmação de que a nação é a unidade natural da associação humana e que o Estado é seu instrumento, historicamente, "um povo" foi formado por meio de coerção ou oportunidade, e a construção do Estado ocorreu sem a etnia, língua, religião e costumes compartilhados. As esperanças democráticas estão ligadas a uma visão dos seres humanos como maleáveis e uma mentalidade de julgamento político fundamentado capaz de identificar o que é politicamente necessário, viável e desejável ao equilibrar reivindicações válidas concorrentes na ausência de respostas objetivamente corretas. Na Europa, as instituições civilizadoras se juntaram às mudanças na personalidade humana, nos modos e na autodisciplina. Os códigos de conduta pública e as expectativas foram internalizados, reduzindo o uso da violência privada (ELIAS, 1994, p. 443-456). Rousseau (1967, p. 58) argumenta que os costumes e as maneiras escritos nos corações dos cidadãos são mais importantes do que as leis formais.

As democracias precisam de democratas - cidadãos com uma mentalidade cívica e habilidades -, e uma importante tarefa das instituições é assegurar o desenvolvimento ético-moral e intelectual dos cidadãos, tornando-os aptos a governar e ser governados (ARISTÓTELES, 1962, p. 216 e 299; MILL, 1962, p. 30-35). Adquirir habilidades e valores e internalizar a tolerância para o desacordo e a vontade de se comprometer, evitando o doutrinamento e a manipulação (FRIEDRICH, 1939), 
são partes importantes da educação democrática. Ainda assim, as demonstrações não são constituídas em um único ato (SCHERZ, 2013, p. 9), e não há uma teoria acordada da educação democrática (DAHL; LINDBLOM, 1953, p. 522-523; WOLIN, 1960, p. 390). Provavelmente, as democracias precisam redescobrir os propósitos democráticos da educação (McDonnell; TIMPANE; BENJAMIN, 2000).

As instituições unem políticas e trazem ordem temporária, mas as democracias estão sempre em processo de transformação. Não obstante os termos de mudança de ordem, declarações do fim da ideologia (BELL, 1960) e da história (FuKuYAMA, 1992). As políticas emergem, se desenvolvem e desaparecem. Há institucionalização e desinstituição, integração e desintegração, formação e descentralização de centros, politização e desproposição, democratização e desdemocratização, constitucionalização e desconstitucionalidade, nacionalização e desnacionalização, profissionalização e desprofissionalização. Todo período histórico contém ideias que transcendem a ordem (MANNHEIM, 1968, p. 193) e os quadros interpretativos (MARX, 1847) existentes. ${ }^{14}$ As democracias devem, continuamente, (re)criar um senso de comunidade, argumentando sobre regras aceitáveis para a convivência (PÉREZ-DíAz, 2017). Elas equilibram a exploração eficiente de alternativas conhecidas e a exploração de novas (MARCH, 1991). Há períodos de estabilidade e dependência da trajetória e também conjunturas de ruptura - estados sem precedentes e inesperados envolvendo mudanças rápidas e indeterminismo (CAPOCCIA; KELEMEN, 2007). Existem boas razões para atender à fragilidade das instituições (OLIVER, 1992) e precaver a instabilidade da autoridade carismática, promovendo a possibilidade de mudanças drásticas (WEBER, 1964, p. 361, 1978, p. 1117).

As tentativas intencionais para projetar a ordem política são uma preocupação central. Demandas de accountability desafiadoras da ordem às vezes apresentam uma visão de uma política ideal. No entanto, foi questionado "se as sociedades dos homens são realmente capazes ou não de estabelecer o bom governo a partir da reflexão e da escolha, ou se elas são para sempre destinadas em suas constituições políticas por acidentes e força" (HAMILTON; JAY; MADISON, 1964, p. 1). Às vezes, o design institucional como meio para alcançar determinados fins desejáveis é uma parte menor dos processos de ordem, sob a forma de uma ecologia dos processos de mudança e da deriva histórica. Os momentos históricos podem ser "muito longos" (HERZOG, 1989, p. 39), e é mais fácil mudar as regras legais do que as práticas políticas e alcançar as consequências pretendidas através de um design deliberado (OLSEN, 2007, 2010).

\footnotetext{
${ }^{14} \mathrm{Em}$ relação ao papel das aspirações, "uma casa pode ser grande ou pequena. Enquanto as casas vizinhas são igualmente pequenas, ela satisfaz todas as exigências sociais para uma residência. Mas se for levantado ao lado da pequena casa um palácio, a casinha encolhe para uma cabana " (MARX, 1847).
} 
As democracias modernas normalmente têm a capacidade de implementar apenas reformas incrementais e remover obstáculos a uma política e sociedade melhores, ao mesmo tem po em que lidam com problemas práticos. O design top-down compete com os processos de bottom-up, transformando a experiência em regras, regras em princípios, princípios em instituições e instituições em ordens políticas, e o caso europeu ilustra que demandas de accountability desafiadora da ordem definem limites para o que é considerado uma ordem aceitável. Os compromissos são organizados em torno de misturas cambiantes de "linhas vermelhas" que funcionam como restrições independentes (CYERT; MARCH, 1963), definindo o que é politicamente possível e desejável, legalmente correto, economicamente racional, cientificamente verdadeiro, tecnicamente possível, administrativamente viável, socialmente justo e cultural e religiosamente apropriado.

O patrimônio do lluminismo europeu glorifica a agência, a reflexão e a ação racionais, o controle humano, a ordem política baseada na razão e o progresso através da aprendizagem experiencial: o indivíduo emancipado da autoridade, alcançando liberdade de pensamento, expressão e associação e autogoverno. Uma premissa básica da democracia é que há escolha. A vida política não é completamente aleatória ou determinista (MARCH; OLSEN, 1995). Ainda assim, as teorias da accountability precisam explorar se as visões democráticas da modernidade superam o alcance da racionalidade e controle humanos em relação à organização, associação e atores políticos (COHEN; MARCH; OLSEN, 2012; MARCH, 2015). Há situações governadas por rotinas institucionais e "políticas como de costume". Existem também situações mal estruturadas - difíceis de prever, compreender, avaliar e controlar por meio das rotinas institucionais existentes - em que as questões exigem ação sem muito tempo para análise, deliberação, barganha, ou construção da coalizão. Existem fatores parecidos com o destino fora do controle dos decisores políticos, e a natureza aberta das políticas democráticas e a possibilidade de mobilizar atores e questões facilitam a espontaneidade e os eventos. Assim, um desafio é compreender as possibilidades e limitações da escolha e da aprendizagem pelo ser humano em contextos caracterizados por padrões normativos ambíguos e cambiantes, fatos e causalidade incertos, e controle limitado. Estudos baseados no modelo de garbage can exploram tais condições. Existem elementos casuais e interações imprevisíveis entre fluxos de problemas, soluções, participantes e oportunidades de escolha. Os resultados são produtos não intencionais de atos e processos interativos, mas não coordenados, sugerindo uma compreensão temporal dos eventos em vez de uma compreensão intencional e consequente (COHEN; MARCH; OLSEN, 1972, 2012).

Em suma, a Europa tenta lidar com suas próprias crises e ações de equilíbrio. Os processos de accountability são parte da prevenção de comportamentos não autorizados e abuso de poder. No entanto, o aumento das demandas de 
accountability desafiadoras da ordem política exige que elas também façam parte da formação e da mudança de ordens. A racionalidade e o controle político podem não corresponder aos padrões do lluminismo e há uma necessidade de realismo quanto ao que os cidadãos e os representantes eleitos podem fazer em contextos complexos e dinâmicos. Existem, no entanto, motivos de confiança e não de desespero. Aristóteles ensinou que aprender a viver juntos "pode ser um longo processo; pois, assim como um estado não pode ser feito de qualquer coleção de pessoas, assim também não pode ser feito a qualquer momento pela vontade" (ARISTótELES, 1962, p. 196). A busca da unidade em meio a tensões irreversíveis é familiar do discurso histórico sobre os fundamentos normativos e organizacionais da governança democrática e da convivência civilizada. Embora esse discurso não forneça respostas definitivas para entender o papel dos processos de accountability em atos de equilíbrio democrático em uma era desafiadora, ele oferece um quadro promissor para uma conversa mais aprofundada sobre regras democráticas para a convivência. Em uma era de transformação, ambiguidade, incerteza e controle limitado, pode ser frutífero ouvir a conversa, e talvez as crianças brincando.

\section{Referências bibliográficas}

AAlberg, T. et al. Populist political communication in Europe. London: Routledge, 2017.

ARISTÓTELES. (384-322 B.C.). The politics. Harmondsworth: Penguin, 1962.

AYRAULt, J-M.;StEInMEIER. F. W. A strong Europe in a world of uncertainties. Voltaire Network, 27 June 2016. Disponível em: <www.voltairenet.org/article192564.html >Acesso em: 15/09/2016.

BALL, T.;FARR, J.; HANSON, R. L. (Eds.). Political innovation and conceptual change. Cambridge: Cambridge University Press, 1989.

BARBer, B. Strong democracy. Participatory politics for a new age. Berkeley: University of California Press, 1984.

BARTL, M. Internal market rationality, private law and the direction of the Union: resuscitating the market as the object of the political. European Law Journal, v. 21, n. 5, p. 572-598, 2015.

BATTISTA, E.; SETARI, N.; RossignOL, E. The mind and body of Europe: a new narrative. Luxemburg: Publication Office, 2014.

BELL, D. The end of ideology: on the exhaustion of political ideas in the fifties. Glencoe IL: Free Press, 1960.

BENDIX, R. Max Weber an intellectual portrait. Garden City NY: Anchor Doubleday, 1962.

BERMAN, H. J. Law and revolution. The formation of the Western legal tradition. Cambridge MA: Harvard University Press, 1983. 
VON BILLERBECK, S. B. K. UN peace operations and conflicting legitimacies. Journal of Intervention and Statebuilding, v. 11, n. 3, p. 286-305, 2017.

BORMANN, N-C.; WINZEN, T. The contingent diffusion of parliamentary oversight institutions in the European Union. European Journal of Political Research, v. 55, p. 589-608, 2016.

BOROWIAK, C. T. Accountability \& Democracy. The pitfalls and promises of popular control. Oxford: Oxford University Press, 2011.

BorowsKI, M. The beginnings of Germany's Federal Constitutional Court. Ratio Juris, v. 16, n. 2, p. 155-186, 2003.

BÖRZEL, T. From EU governance crisis to crisis of EU governance: regulatory failure, redistributive conflict and Eurosceptic publics. Journal of Common Market Studies, v. 54, Annual Review, p. 8-31, 2016.

Bourke, R.; Geuss, R. Introduction. In: Bourke, R.; Geuss, R. (Eds.). Political judgement. Cambridge: Cambridge University Press, 2009. p. 1-26.

Boussaguet, L. Participatory mechanisms as symbolic policy instruments? Comparative European Politics, v. 14, n. 1, p. 107-124, 2016.

BOVENS, M. Two concepts of accountability: accountability as a virtue and as a mechanism. West European Politics, v. 33, n. 5, p. 946-967, 2010.

BOVENS, M.; CURTIN, D.; 'T HART, P. (Eds.). The real world of EU accountability. What deficit? Oxford: Oxford University Press, 2010.

Bovens, M.; Goodin, R. E.; SCHILlemans, T. (Eds.). The Oxford Handbook of Public Accountability. Oxford: Oxford University Press, 2014.

Brandsma, G. J.; Heidbreider, E; MAastenbroek, E. Accountability in the postLisbon European Union. International Review of Administrative Sciences, v. 82, n. 4, p. 621-637, 2016.

BRÄNDSTRÖM, A. Crisis accountability: ministerial resignation in Sweden. Scandinavian Political Studies, v. 38, n. 3, p. 301-320, 2015.

BRENNAN, G.; BUCHANAN, J. M. The reasons of rules. Constitutional political economy. Cambridge: Cambridge University Press, 1985.

BRUNSSON, N.; OLSEN, J. P. Organization theory: thirty years of dismantling, and then ... ? In: BRUNSSON, N.; OLSEN, J. P. (Eds.). Organizing organizations. Bergen: Fagbokforlaget, 1998. p. 13-43.

BusuIOC, M. The accountability of European agencies. Legal provisions and ongoing practices. Delft: Eburon, 2010.

Busuioc, M.; GROENLEER, M.; TRONDAL, J. The agency phenomenon in the European Union: emergence, institutionalisation and everyday decision-making. Manchester: Manchester University Press, 2012.

CAPOCCIA, G.; KELEMEN, R. D. The study of critical junctures. Theory, narrative, and counterfactuals in historical institutionalism. World Politics, v. 59, n. 3, p. 341-369, 2007.

CARAMANI, D. Will vs. reason: the populist and technocratic forms of political representation and their critique of party government. American Political Science Review, v. 111, n. 1, p. 54-67, 2017. 
Carpenter, D.; Krause, G. A. Transactional authority and bureaucratic politics. Journal of Public Administration Research and Theory, v. 25, n. 1, p. 5-25, 2015.

ChALMERS, D.; JACHTENFUCHS, M.; JOERGES, C. (Eds.). The end of the Eurocrats' dream. Adjusting to European diversity. Cambridge: Cambridge University Press, 2016.

Christensen, T.; LAEgREID, P. (Eds.). The Routledge Handbook to Accountability and Welfare State Reforms in Europe. London: Routledge, 2017.

COHEN, M. D.; MARCH, J. G.; OLSEN, J. P. A garbage can model of organizational choice. Administrative Science Quarterly, v. 17, p. 1-25, 1972.

COHEN, M. D.; MARCH, J. G.; OLSEN, J. P. "A garbage can model" at forty: a solution that still attracts problems. In: LOMI, A.; HARRISON, J. R. (Eds.). The garbage can model of organizational choice: looking forward at forty. Bingley: Emerald Books, 2012. p. 19-30.

COUNCIL OF EUROPE. State of democracy, human rights and the rule of law. Populism - how strong are Europe's checks and balances? Strasbourg: Report by the Secretary General of the Council of Europe, 2017.

CREMADES, M. T.; NovAK, P. Brexit and the European Union: general institutional and legal considerations. Brussels: Directorate General for Internal Policies of the Union, 2017. Disponível em: http://www.europarl.europa.eu/supporting-analyses

CRICK, B. In Defence of Politics. 2. ed. Harmondsworth: Penguin Books, 1982 [1962]. CRUM, B.; FOSSUM, J. E. The multilevel parliamentary field: a framework for theorizing representative democracy in the EU. European Political Science Review, v. 1, n. 2, p. 249-271, 2009.

CURTIN, D. "Accountable independence" of the European Central Bank: seeing the logics of transparency. European Law Journal, v. 23, n. 1-2, p. 28-44, 2017.

CYERT, R. M.; MARCH, J. G. A behavioral theory of the firm. Englewood Cliffs, NJ: Prentice Hall, 1963. 2. ed. Oxford: Basil Blackwell, 1992.

DAHL, R. A. Who governs. Democracy and power in an American city. New Haven: Yale University Press, 1961.

DAHL, R. A. A preface to democratic theory. Chicago: University of Chicago Press, 1963 [1956].

DAHL, R. A. Democracy and its critics. New Haven: Yale University Press, 1989.

DAHL, R. A. The shifting boundaries of democratic governments. Social Research, $v$. 66, n. 3, p. 915-931, 1999.

DAHL, R. A.; Lindblom, C. E. Politics, economics, and welfare. New York: Harper Torchbooks, 1963 (paperback) [1953].

DAHRENDORF, R. The modern social conflict. An essay on the politics of liberty. London: Weidenfeld and Nicolson, 1988.

DALton, R. J.; KLINGEMANN, H-D. Citizens and political behavior. In: Dalton, R. J.; KLINGEMANN, H-D. (Eds.). The Oxford Handbook of Political Behavior. Oxford: Oxford University Press, 2007. p. 3-26.

DAwson, M. The legal and political accountability structure of "post-crisis" EU economic governance. Journal of Common Market Studies, v. 53, n. 5, p. 976-993, 2015. 
DAWSON, J.; HANLEY, S. What is wrong with East-Central Europe? The fading mirage of the "liberal consensus". Journal of Democracy, v. 27, n. 1, p. 20-34, 2016.

DE WILDE, P.; TRENZ, H-J. Denouncing European integration: Euroscepticism as polity contestation. European Journal of Social Theory, v. 15, n. 4, p. 537-554, 2012.

DIAMOND, L. Three paradoxes of democracy. Journal of Democracy, v. 1, n. 3, p. 4860, 1990.

DIAMOND, L. Future of democracy. In: CLARKE, P. B.; FoWERAKER, J. (Eds.). Encyclopedia of Democratic Thought. London: Routledge, 2001. p. 154-161.

DRYZEK, J. S.; HONIG, B.; PHILLIPS, A. Introduction. In: DRYZEK, J. S.; HONIG, B.; PHILLIPS, A. The Oxford Handbook of Political Theory. Oxford: Oxford University Press, 2006. p. 3-41.

DURÁN, I. P. Accountability from the perspective of the forum: citizens' attitudes towards accountability in Europe. West European Politics, v. 39, n. 4, p. 835-858, 2016.

DURKHEIM, E. L'Individualism et les Intellectuels. Reprinted, with an introduction by Steven Lukes: Individualism and the intellectuals, Political Studies, v. 17, n. 1, p. 14-30, 1969

Duverger, M. Political parties. London: Methuen (University paperbacks), 1964 [1951].

DUVERgER, M. The idea of politics. The use of power in society. London: Methuen, 1966. Egeberg, M. (Ed.). Multilevel Union administration. The transformation of executive politics in Europe. Houndmills: Palgrave MacMillan, 2006.

ELIAS, N. The civilizing process. Oxford: Blackwell, 1994 [1939].

ENNSER-JEDENASTIK, L. The politicization of regulatory agencies: between partisan influence and formal independence. Journal of Public Administration Research and Theory, v. 26, n. 3, p. 507-518, 2016. doi: 10.1093/jopart/muv022

ERIKSEN, E. O.; FOSSUM, J. E. (Eds.). Rethinking democracy and the European Union. London: Routledge, 2012.

EUROPEAN COMmISSION. Completing Europe's Economic and Monetary Union. Brussels: Report by Jean-Claude Juncker, 2015. In close cooperation with Donald Tusk, Jeroen Dijsselbloem, Mario Draghi and Martin Schulz.

EUROPEAN COMMISSION. State of the Union address 2016: towards a better Europe - a Europe that protects, empowers and defend. 2016. Disponível em: <http:// ec.europa.eu/priorities/state-union-2016 >Acesso em: 17/09/2016.

EUROPEAN COMMISSION. White paper on the future of Europe. Reflections and scenarios for the EU27 by 2025. 2017. Disponível em: <https://ec.europa.eu/ commission/sites/beta-political/files/white_paper_on_the_future_of_europe_ en.pdf >Acesso em: 02/03/2017.

EURopeAn Council. Bratislava Declaration and Roadmap. Brussels: Press Office general Secretariat of the Council, 2016. Disponível em: <www.consilium.europa. eu/press> Acesso em: 17/09/2016.

EUROPEAN COUnCIL. The Rome Declaration. Brussels: Press release 149/17, 2017. 
FABBRINI, S. The euro crisis through two paradigms: interpreting the transformation of the European economic governance. European Politics and Society, v. 18, n. 3, p. 318-332, 2016. http:dx.doi.org/10.1080/23745118.2016.1229387.

Ferguson, Y. H.; Mansbach, R. W. Polities. Authority, identities and change. Columbia SC: University of South Carolina Press, 1996.

FILGUEIRAS, F. Transparency and accountability: principles and rules for the construction of publicity. Journal of Public Affairs, v. 16, n. 2, p. 192-202, 2016.

FoA, R. S.; Mounck, Y. The danger of deconsolidation. The democratic disconnect. Journal of Democracy, v. 27, n. 3, p. 6-17, 2016.

FøLLESDAL, A.; HIX, S. Why there is a democratic deficit in the European Union. Journal of Common Market Studies, v. 44, n. 3, p. 533-562, 2006.

FrIEDRICH, C. J. Democracy and dissent. Political Quarterly, p. 571-582, OctoberDecember 1939.

FUKUYAMA, F. The end of history and the last man. New York: Avon Books, 1992.

GAILMARD, S. Accountability and principal-agent theory. In: BOVENS, M.; GOODIN, R. E.; SCHILlemans, T. (Eds.). The Oxford Handbook of Public Accountability. Oxford: Oxford University Press, 2014. p. 90-105.

Glazer, N. Democracy and deep divides. Journal of Democracy, v. 21, n. 2, p. 5-19, 2010.

Goodin, R. E. Enfranchising all affected interests, and its alternatives. Philosophy \& Public Affairs, v. 35, n. 1, p. 40-68, 2007.

Goodin, R. E. Innovating democracy. Democratic theory and practice after the deliberative turn. Oxford: Oxford University Press, 2008.

GoodIN, R. E. Introduction. The state of the discipline. In: GoodIN, R. E. (Ed.). The Oxford Handbook of Political Science. Oxford: Oxford University Press, 2009. p. 3-57. GoodIN, R. E. On settling. Princeton: Princeton University Press, 2012.

GRANT, R. W.; KeOHANE, R. O. Accountability and abuses of power in world politics. American Political Science Review, v. 99, n. 1, p. 29-43, 2005.

GRUBE, D. C. Administrative learning or political blaming? Public servants, parliamentary committees and the drama of public accountability. Australian Journal of Political Science, v. 49, n. 2, p. 221-236, 2014.

GustaVsson, S.; KARLSSON, C.; PerSSON, T. (Eds.). The illusion of accountability in the European Union. London: Routledge, 2009.

GutManN, A.; ThOMPSON, D. The mindset of political compromise. Perspectives on Politics, v. 8, n. 4, p. 1125-1143, 2010.

GYORFI, T. Against the new constitutionalism. Cheltenham: Edgar Elgar, 2016.

HALL, J. A. The politics of modernity. In: Engelstad, F.; ØSterud, $\varnothing$. (Eds.). Power and democracy. Critical interventions. Aldershot: Ashgate, 2004. p. 131-150.

Hamilton, A.; JAY, J.; MAdison, J. The Federalist Papers. New York: Pocket Books, Simon \& Schuster, 1964 [1787].

HAY, C.; STOKER, G. Revitalizing politics: have we lost the plot? Representation, v. 45, n. 3, p. 225-236, 2009. 
Herzog, D. Happy slaves. A critique of consent theory. Chicago: The University of Chicago Press, 1989.

HM GOVERNMENT. The United Kingdom's exit from and new partnership with the European Union. White Paper, Cm 94172017.

HoввES, T. Leviathan. (ed. and abridged with an introduction by John Plamenatz) London: The Fontana Library, 1962 [1651].

Новоцт, S. В. The Brexit vote: a divided nation, a divided continent. Journal of European Public Policy, v. 23, n. 9, p. 1259-1277, 2016.

HовоLт, S. B.; TILLEY, J. Blaming Europe? Responsibility without accountability in the European Union. Oxford: University Press, 2014.

HOOGHE, L.; MARKS, G. Multi-level governance and European integration. Lanham: Rowman \& Littlefield, 2001.

HoY, T. (Ed.). Politics \& Power. Who should rule? New York: Capricorn Books, 1968.

ISSACHAROFF, S.; PILDES, R. H. Politics as markets: partisan lockups of the democratic process. Stanford Law Review, v. 50, n. 3, p. 643-717, 1998.

JACHTENFUCHS, M.; DIEZ, T.; JUNG, S. Which Europe? Conflicting models of a legitimate European political order. European Journal of International Relations, v. 4, n. 4, p. 409-455, 1998.

JOERGES, C. Integration through law and the crisis of law in Europe's emergency. In: Chalmers, D.; JaChtenfuchs, M.; JOERGES, C. (Eds.). The end of the Eurocrats' dream. Adjusting to European diversity. Cambridge: Cambridge University Press, 2016. p. 299-338

Joerges, C.; Kreuder-Sonnen, C. European studies and the European crisis: legal and political science between critique and complacency. European Law Journal, v. 23, n. 1-2, p. 118-139, 2017. DOI: 10.1111/eulj.12225

JUNCKER, J-C. State of the Union address 2017. Brussels: Speech/17/3165, 2017. Disponível em: http://europa.eu/rapid/press-release_SPEECH-17-3165_en.htm KELSEN, H. Foundations of democracy. Ethics, v. 66, n. 1, p. 1-101, 1955.

KLIJN, E. H.; Koppenjan, J. F. M. Accountable networks. In: Bovens, M.; Goodin, R. E.; SCHILlemans, T. (Eds.). The Oxford Handbook of Public Accountability. Oxford: Oxford University Press, 2014. p. 242-257.

Kochenov, D.; MAGEN, A.; PECH, L. (Eds.). The JCMS Symposium 2016: the great rule of law debate in the EU. Journal of Common Market Studies, v. 54, n. 5, p. 10451049, 2016.

Kornhauser, W. The politics of mass society. New York: Free Press, 1959.

KRAMPF, A. From transparency to accountability: the impact of the ECB's unconventional policies on the EMU. Journal of European Integration, v. 38, n. 4, p. 455-471, 2016.

KRATOCHWIL, F. Has the "Rule of law" become a "rule of Lawyers"? In: PALOMBelLA, G.; WALKeR, N. (Eds.). Relocating the Rule of Law. Oxford and Portland: Hart Publishing, 2009. p. 171-196.

KYDLAND, F. E.; PRESCOT, E. C. Rules rather than discretion: the inconsistency of optimal plans. Journal of Political Economy, v. 85, n. 3, p. 473-491, 1977. 
KYMLICKA, W. Solidarity in diverse societies: beyond neoliberal multiculturalism and welfare chauvinism. Comparative Migration Studies, v. 3, n. 17, p. 3-17, 2015.

LEVER, A. Democracy and judicial review: are they really incompatible. Perspectives on Politics, v. 7, n. 4, p. 805-822, 2009.

LIPSET, S. M.; ROKKAN, S. Cleavage structures, party systems, and voter alignments: an introduction. In: LIPSET, S. M.; ROKKAN, S. (Eds.). Party systems and voters alignments. New York: Free Press, 1967. p. 1-64.

LOEWENSTEIN, K. The Union of Western Europe: illusion and reality. Columbia Law Review, v. 52, n. 1, p. 55-99, 1952.

Machiavelli, N. The Prince and The Discourses. New York: Random House: The Modern Library, 1940 [1513/1532, 1513/1517].

MACINTYRE, A. Whose justice? Which rationality? Notre Dame: University of Notre Dame Press, 1988.

MAGEN, A. Cracks in the foundations: understanding the Great Rule of Law Debate in the EU. Journal of Common Market Studies, v. 54, n. 5, p. 1050-1061, 2016.

MAggetTI, M.; PAPAdopoulos, Y. The principal-agent framework and independent regulatory agencies. Political Studies Review, v. 14, n. 4, p. 1-12, 2016. DOI: 10.1177/1478929916664359

MAIER, C. S. Changing boundaries of the political: essays on the evolving balance between the State and society, public and private in Europe. Cambridge: Cambridge University Press, 1987.

MAIR, P. Political opposition and the European Union. Government and Opposition, v. 42, n. 1, p. 1-17, 2007.

MAIR, P. Ruling the void: the hollowing-out of Western democracy. London: Verso, 2013.

MAJONE, G. Europe's "democratic deficit": the question of standards. European Law Journal, v. 4, n. 1, p. 5-28, 1998.

MAJONE, G. Rethinking the Union of Europe post-crisis: has integration gone too far? Cambridge: Cambridge University Press, 2014.

MANNHEIM, K. Ideology and utopia. New York: Harcourt, Brace \& World, 1968, [1929].

MARCH, J. G. Footnotes to organizational change. Administrative Science Quarterly, v. 26, n. 4, p. 563-577, 1981.

MARCH, J. G. Exploration and exploitation in organizational learning. Organizational Science, v. 2, p. 71-87, 1991.

MARCH, J. G. The ambiguities of experience. Ithaca: Cornell University Press, 2010.

MARCH, J. G. Do the mistakes lie in decision makers or in economics? In: RANGAN, S. (Ed.). Performance and Progress. Oxford: Oxford University Press, 2015. p. 28-37.

MARCH, J. G.; OLSEN, J. P. Ambiguity and choice in organizations. Bergen: Universitetsforlaget, 1976.

MARCH, J. G.; OLSEN, J. P. Organizing political life: what administrative reorganization tells us about government. The American Political Science Review, v. 77, n. 2, p. 281-296, 1983. 
MARCH, J. G.; OLSEN, J. P. The New Institutionalism: organizational factors in political life. American Political Science Review, v. 78, p. 734-749, 1984.

MARCH, J. G.; OLSEN, J. P. Rediscovering institutions. The organizational basis of politics. New York: Free Press, 1989.

MARCH, J. G.; OLSEN, J. P. Democratic governance. New York: Free Press, 1995.

MARCH, J. G.; OLSEN, J. P. Elaborating the "New Institutionalism". In: RHODES, R. A. W.; BINDER, S. A.; RockMAN, B. A. (Eds.). The Oxford Handbook of Political Institutions. Oxford: Oxford University Press, 2006. p. 3-20.

March, J. G.; Schulz, M.; Zhou, X. The dynamics of rules. Change in written organizational codes. Stanford CA: Stanford University Press, 2000.

MARCH, J. G.; SIMON, H. A. Organizations. New York: Wiley, 1958.

MARX, K. Wage labor and capital. Relation of wage-labor to capital. 1847. Disponível em: <https://www.marxists.org/archive/marx/works/1847/wage-labour/index. htm $><$ Acesso em: 21/02/2017.

MAY, T. The government's negotiating objectives for exiting the EU. 2017. Disponível em: < https://www.gov.uk/government/speeches/the-governments-negotiatingobjectives-for-exiting-the-eu-pm-speech >

McDonnell, L. M.; TIMPAne, P. M.; Benjamin, R. (Eds.). Rediscovering the democratic purposes of education. Lawrence: University Press of Kansas, 2000.

MCNAMARA, K. R. Rational fictions: central bank independence and the social logic of delegation. West European Politics, v. 25, n. 1, p. 47-76, 2002.

MenÉndez, A. J. Editorial. Hermann Heller NOW. European Law Journal, v. 21, n. 3, p. 285-294, 2015.

MENÉNDEZ, A. J. The guardianship of European constitutionality. A structural critique of European constitutional review. Oslo: University of Oslo, ARENA Working Paper 2/2017.

MÉNY, Y. Conclusion: a voyage to the unknown. Journal of Common Market Studies, v. 50, p. 154-164, 2012.

MICHALSKY, A.; NORMAN, L. Conceptualizing European security cooperation: competing international political orders and domestic factors. European Journal of International Relations, v. 22, n. 4, p. 749-772, 2016.

MiChels, A.; MeIJER, A. Safeguarding public accountability in horizontal government. Public Management Review, v. 10, n. 2, p. 165-173, 2008.

MILL, J. S. Considerations on representative government. South Bend IN: Gateways editions, 1962 [1861].

MILL, J. S. On liberty. Indianapolis: Bobbs-Merrill, 1977 [1859].

MISES INSTITUTE. The end of politics. Mises Institute, 2016. (https://mises.org/ events/end-politics)

Montesquieu, Charles de Secondat baron de. The spirit of the laws. Cambridge: Cambridge University Press, 1989 [1748]. 
MonTI, M. et al. Future financing of the EU. Final Report and Recommendations of the High Level Group on Own Resources. Comissão Europeia, 2016. Disponível em: ec.europa.eu/budget/mff/hlgor Acesso em: 20/01/2017.

MoRAVCSIK, A. Is there a 'democratic deficit' in world politics? A framework for analysis. Government and Opposition, v. 39, n. 2, p. 336-363, 2004.

MoufFE, C. The return of the political. London: Verso, 2005.

MüLLER, J-W. Contesting democracy. Political ideas in twentieth century Europe. New Haven: Yale University Press, 2011.

NAERT, F. The new European Union economic governance: what about accountability. International Review of Administrative Sciences, v. 82, n. 4, p. 638-655, 2016.

NÄSström, S. The challenge of the all-affected principle. Political Studies, v. 59, p. 116-134, 2011.

NORMAN, L. Defending the European political order: visions of politics in response to the radical right. European Journal of Social Theory, v. 20, n. 4, p. 1-19, 2016. https://doi.org/10.1177/1368431016679670

NYBERG, L. Politikens handlingsutrymme och konkurrensens lagar. Nyliberale föreställningar om stat och marknad i tre konkurrensregelverk. Statsvetenskaplig Tidskrift, v. 117, n. 4, p. 505-530, 2015.

OFFE, C. Contradictions of the Welfare State. (edited and with an introduction by J. Keane) Cambridge Ma: The MIT Press, 1984.

OLIVER, C. The antecedents of deinstitutionalization. Organizational Studies, v. 13, n. 4, p. 563-588, 1992.

OLSEN, J. P. Citizens, public administration and the search for theoretical foundations. PS XXXVII (1), p. 69-79, 2003.

OLSEN, J. P. Europe in search of political order. An institutional perspective on unity/ diversity, citizen/their helpers, democratic design/historical drift, and the coexistence of orders. Oxford: Oxford University Press, 2007.

OLSEN, Johan P. Democratic government, institutional autonomy and the dynamics of change. West European Politics, v. 32, n. 3, p. 439-465, 2009.

OLSEN, J. P. Governing through institution building. Institutional theory and recent European experiments in democratic organization. Oxford: Oxford University Press, 2010.

OLSEN, J. P. Democratic accountability, political order, and change. Exploring accountability processes in an era of European transformation. Oxford: Oxford University Press, 2017.

ORGANIZATION FOR ECONOMIC COOPERATION AND DEVELOPMENT (OECD). In it together: why less inequality benefits all. Overview of inequality trends, key findings and policy directions. Paris: OECD, 2015.

OWEN, D. Constituting the polity, constituting the demos: on the place of all the affected interests principle in democratic theory and in resolving the democratic boundary problem. Ethics \& Global Politics, v. 5, n. 3, p. 129-152, 2012.

PAPADOPOULOS, Y. Accountability and multi-level governance: more accountability less democracy? West European Politics, v. 33, n. 5, p. 1030-1049, 2010. 
PAPADOPOUlOS, Y. Democracy in crisis? Politics, governance and policy. Houndmills: Palgrave MacMillan, 2013.

PÉREZ-DíAz, V. (Paperback Ed.). Introduction: free markets, civil societies and a liberal polity. In: Pérez-Díaz, V. Markets and civil society. The European experience in comparative perspective. New York: Berghahn, 2014.

PÉREZ-DíAz, V. The sleep of reason produces monsters: on the subject of civic demands and capacities today. Research Paper 110(b)/2017. Madrid: Analistas Socio-Politicos, 2017.

PÉREZ DURÁN, I. Accountability from the perspective of the forum: citizens' attitudes toward accountability in Europe. West European Politics, v. 39, n. 4, p. 815-858, 2016.

Perry, M. J. Morality, politics \& law. Oxford: Oxford University Press, 1988.

PETTIT, P. Depoliticizing democracy. Ratio Juris, v. 17, n. 1, p. 52-65, 2004.

PIERRE, J. Reinventing governance, reinventing democracy. Policy \& Politics, v. 37, p. 591-609, 2009.

PIRIS, J-C. The Lisbon Treaty. A legal and political analysis. Cambridge: Cambridge University Press, 2010.

POLANYI, K. The great transformation. The political and economic origins of our time. Boston: Beacon, 1957 [1942].

PollitT, C.; HUPE, P. Talking about government. The role of magic concepts. Public Management Review, v. 13, n. 5, p. 641-658, 2011.

PREUSS, U. K. Prospects of a constitution of Europe. Constellations, v. 3, n. 2, p. 209224, 1996.

RAUH, C.; WILDE, P. The opposition deficit in EU accountability: evidence from over 20 years of plenary debate in four member states. European Journal of Political Research, early view, 2017. doi: 10.1111/1475-6765.12222

RENWICK, A. The process of Brexit: what comes next? Working paper. London: UCL European Institute, 2017.

REYKOWSKI, J. Why did the collectivist state fail? Theory and Society, v. 23, p. 233252, 1994.

Rhodes, R. A. W.; Binder, S. A.; Rockman, B. A. (Eds.). The Oxford Handbook of Political Institutions. Oxford: Oxford University Press, 2006.

RoKKAN, S. Norway: numerical democracy and corporate pluralism. In: DAHL, R. A. (Ed.). Political oppositions in Western democracies. New Haven CN: Yale University Press, 1966. p. 70-115.

ROKKAN, S.; URWIN, D. Economy, territory, identity: politics of West European peripheries. London: Sage, 1983.

ROTHSTEIN, B. The quality of government. Corruption, social trust and inequality in international perspective. Chicago: The University of Chicago Press, 2011.

ROUSSEAU. J-J. The social contract and discourse on the origin of social inequality. New York: Washington Square Press, 1967 [1762/1755].

RUBIN, E. L. The myth of accountability and the anti-administrative impulse. Michigan Law Review, v. 103, n. 8, p. 2073-2136, 2005. 
SABINE, G. H. A history of political theory. New York: henry Holt and Company, 1937. SARTORI, G. The theory of democracy revisited. Chatham NJ: Chatham House Publishers, 1987.

SCHARPF, F. W. After the crash: a perspective on multilevel European democracy. European Law Journal, v. 21, n. 3, p. 384-405, 2015.

SCHARPF, F. W. De-constitutionalization and majority rule. A democratic vision for Europe. Cologne: MPIfG Discussion Paper 14/14, 2016.

SCHATTSCHNEIDER, E. E. The semi-sovereign people. New York: Holt, Rinehard and Winston, 1960.

SCHELLING, T. C. Economic reasoning and the ethics of policy. The Public Interest, v. 68,p. 37-61, Spring, 1981.

SCHERZ, A. The legitimacy of the demos: who should be included in the demos and on what grounds? Living Reviews of Democracy, v. 4, p. 1-13, 2013. Disponível em: <http://www.livingreviews.org//rd-2012-1> Acesso em: 12/01/2017.

SCHILLEMANS, T. The public accountability review. A meta-analysis of public accountability research in six academic disciplines. Working Paper. Utrecht: Utrecht University School of Governance, 2013.

SCHILlEMANS, T.; BusUIOC, M. Predicting public sector accountability: from agency drift to forum drift. Journal of Public Administration Research and Theory, v. 25, n. 1, p. 191-215, 2015.

SCHMITT, C. The concept of the political. New Brunswick, NJ: Rutgers University Press, 1976 [1927].

SCHMITTER, P. C. How to democratize the European Union... and why bother? Lanham: Rowman \& Littlefield, 2000.

SCHMITTER, P. C. The ambiguous virtues of democracy. Journal of Democracy, v. 15, n. 4, p. 47-60, 2004.

SCHMITTER, P. C. Comparative politics: its past, present and future. Chinese Political Science Review, v. 1, n. 3, p. 397-411, 2016.

SChumpeter, J. A. Capitalism, socialism \& democracy. London: Routledge, 1994 [1942].

Sedelmeier, U. Europeanization. In: Jones, E.; Menon, A.; Weatherhill, S. (Eds.). The Oxford Handbook of the European Union. Oxford: Oxford University Press, 2012. p. 825-839.

SELZNICK, P. Leadership in administration. New York: Harper and Row, 1957.

SELZNICK, P. The moral commonwealth. Social theory and the compromise of community. Berkeley: University of California Press, 1992.

SIMON, H. A. Administrative behavior. 2. ed. New York: Free Press, 1957.

SIMPSON, K.; LOVELESS, M. Another chance? Concerns about inequality, support for the European Union and further European integration. Journal of European Public Policy, v. 24, n. 7, p. 1067-1089, 2017.

StATham, P.; TREnZ, H-J. The politicization of Europe. Contesting the Constitution in the mass media. London: Routledge, 2013. 
StEPHENSON, P. Starting from scratch? Analysing early institutionalization processes: the case of audit governance. Journal of European Public Policy, v. 23, n. 10, p. 14811501, 2016.

StinchCOMBE, A. L. Social structure and organizations. In: MARCH, J. G. (Ed.). Handbook of Organizations. Chicago: Rand McNally, 1965. p. 142-193.

StONE SWEET, A. The judicial construction of Europe. Oxford: Oxford University Press, 2004.

StREeCK, W. Heller, Schmitt and the Euro. European Law Journal, v. 21, n. 3, p. 361370, 2015.

STR $\varnothing \mathrm{M}, \mathrm{K}$. Delegation and accountability in parliamentary democracies. European Journal of Political Research, v. 37, p. 261-289, 2000.

StrøM, K.; MülleR, W. C.; Bergman, T. (Eds.). Delegation and accountability in parliamentary democracies. Oxford: Oxford University Press, 2003.

ThATCHER, M.; STONE SWEET, A. Theory and practice of delegation to non-majoritarian institutions. West European Politics, v. 25, n. 1, p. 1-22, 2002.

Tocqueville, A. de. Democracy in America, v. 1. New York: Vintage Books, 1945 [1835].

Tocaueville, A. de. The old regime and the French Revolution. Garden City NY: Doubleday Anchor Books, 1955 [1856].

ToWfIGH, E. V. Rational choice and its limits. German Law Journal, v. 17, n. 5 (Special Issue), p. 763-78, 2016.

TRONDAL, J. An emergent European executive order. Oxford: Oxford University Press, 2010.

VIROLI, M. From politics to reason of State. The acquisition and transformation of the language of politics 1250-1600. Cambridge: Cambridge University Press, 1992.

WaldRon, J. Political, political theory: essays on institutions. Cambridge MA: Harvard University Press, 2016.

WARD-PERKINS, B. The fall of Rome and the end of civilization. Oxford: Oxford University Press, 2005.

WEBER, M. (Paperback Ed.). The theory of social and economic organization. New York: Free Press, 1964.

Weber, M. Politics as a vocation. In: Gerth, H. H.; Wright Mills, C. (Eds.). From Max Weber. London: Routledge \& Kegan Paul, 1970. p. 77-128.

WEBER, M. Economy and society. Berkeley: University of California Press, 1978. (Eds. G. Roth e C. Wittich).

WEILER, J. H. H. European neo-constitutionalism: in search of foundations for the European constitutional order. In: BELLAMY, R.; CASTIGLIONE, D. (Eds.). Constitutionalism in transition: European and theoretical perspectives. Oxford: Blackwell, 1996. p. 105-121.

WEILER, J. H. H. Europe in crisis-on the "political Messianism", "legitimacy" and "the rule of law". Singapore Journal of Legal Studies, p. 248-268, 2012. 
Wheeler, H. Constitutionalism. In: Greenstein, F. I.; Polsby, N. W. (Eds.). Handbook of Political Science, Volume 5: Governmental Institutions and processes. Reading MA: Addison-Wesley, 1975. p. 1-91.

WHITE, J. Emergency Europe. Political Studies, v. 63, n. 2, p. 300-318, 2015.

WIESEL, F.; MODELL, S.; MolL, R. Customer orientation and management control in the public sector: a garbage can analysis. European Accounting Review, v. 20, n. 3, p. 551-581, 2011.

WILDAVSKY, A. Choosing preferences by constructing institutions: a cultural theory of preference formation. American Political Science Review, v. 81, p. 3-22, 1987.

WILKInson, M. A. Political constitutionalism and the European Union. Modern Law Review, v. 76, n. 2, p. 191-222, 2013.

WILLE, A. The normalization of the European Commission. Politics and bureaucracy in the EU Executive. Oxford: Oxford University Press, 2013.

WILLE, A. The evolving EU accountability landscape: moving to an ever denser union. International Review of Administrative Sciences, v. 82, n. 4, p. 694-717, 2016.

WIRTH, L. Preface, K. Mannheim: Ideology and Utopia 1968: x-xxx. New York: Harcourt, Brace \& World, 1936.

Wolin, S. S. Politics and vision. Continuity and innovation in Western political thought. Boston: Little, Brown \& co, 1960.

Wright, T. The politics of accountability. In: ELLIOT, M.; FELDMAN, D. (Eds.). The Cambridge companion to public law. Cambridge: Cambridge University Press, 2015. p. 96-115.

YURATICH, D. Article 13(2) TEU: institutional balance, sincere co-operation, and nondominance during lawmaking? German Law Journal, v. 18, n. 1, p. 99-125, 2017.

\section{Johan P. Olsen}

Professor Emérito da University of Oslo, Noruega. Fundador e pesquisador associado do ARENA Centre for European Studies - University of Oslo. Autor de Governing through Institution Building: Institutional Theory and Recent European Experiments in Democratic Organization (Oxford University Press, 2010) e de Democratic accountability, political order and change (Oxford University Press, 2017). Além disso, é autor de vários artigos acadêmicos e ensaios em periódicos internacionais. Contato: j.p.olsen@arena.uio.no 